\title{
Utp14 interaction with the small subunit processome
}

\author{
JOSHUA J. BLACK, ${ }^{1}$ ZHAOHUI WANG, ${ }^{1}$ LISA M. GOERING, ${ }^{2}$ and ARLEN W. JOHNSON ${ }^{1}$ \\ ${ }^{1}$ Department of Molecular Biosciences, The University of Texas at Austin, Austin, Texas 78712, USA \\ ${ }^{2}$ Department of Biological Sciences, St. Edward's University, Austin, Texas 78704, USA
}

\begin{abstract}
The SSU processome (sometimes referred to as $90 \mathrm{~S}$ ) is an early stable intermediate in the small ribosomal subunit biogenesis pathway of eukaryotes. Progression of the SSU processome to a pre-40S particle requires a large-scale compaction of the RNA and release of many biogenesis factors. The U3 snoRNA is a primary component of the SSU processome and hybridizes to the rRNA at multiple locations to organize the structure of the SSU processome. Thus, release of U3 is a prerequisite for the transition to pre-40S. Our laboratory proposed that the RNA helicase Dhr1 plays a crucial role in the transition by unwinding U3 and that this activity is controlled by the SSU processome protein Utp14. How Utp14 times the activation of Dhr1 is an open question. Despite being highly conserved, Utp14 contains no recognizable domains, and how Utp14 interacts with the SSU processome is not well characterized. Here, we used UV crosslinking and analysis of cDNA (CRAC) and yeast two-hybrid interaction to characterize how Utp14 interacts with the preribosome. Moreover, proteomic analysis of SSU particles lacking Utp14 revealed that the presence of Utp14 is needed for efficient recruitment of the RNA exosome. Our analysis positions Utp14 to be uniquely poised to communicate the status of assembly of the SSU processome to Dhr1 and possibly to the exosome as well.
\end{abstract}

Keywords: Utp14; exosome; SSU processome; $40 \mathrm{~S}$

\section{INTRODUCTION}

Ribosomes are the complex and dynamic molecular machines that decode genetic information into protein. In Saccharomyces cerevisiae, the ribosomal large subunit (LSU or $60 \mathrm{~S}$ ) is composed of three ribosomal RNA (rRNA) molecules (25S, 5.8S, 5S) and 46 ribosomal proteins (r-proteins), and the small subunit (SSU or 40S) consists of the 18S rRNA and 33 r-proteins (Ben-Shem et al. 2011). Ribosome synthesis begins in the nucleolus with cotranscriptional recruitment of assembly factors to the polycistronic $35 \mathrm{~S}$ transcript. The $35 \mathrm{~S}$ pre-rRNA undergoes extensive modification and processing, coordinated with RNA folding and protein assembly, to generate the pre-40S and pre-60S particles, which are subsequently exported to the cytoplasm where the final steps of maturation occur (for recent reviews, see Sloan et al. 2016; Kressler et al. 2017; Peña et al. 2017).

An early stable intermediate of $40 \mathrm{~S}$ assembly is the SSU processome, a large complex of $\sim 6 \mathrm{MDa}$ containing the $5^{\prime}$-portion of the $35 \mathrm{~S}$ pre-rRNA transcript, the $5^{\prime}$-external transcribed spacer (5'-ETS), $18 \mathrm{~S}$ and a portion of the internal transcribed spacer 1 (ITS1) (Barandun et al. 2018). The SSU processome also contains the U3 snoRNA and approximately 70 assembly factors (Dragon et al. 2002; Chaker-Margot et al. 2015; Zhang et al. 2016). Although the SSU processome is sometimes referred to as the $90 \mathrm{~S}$ preribosomal complex, we

Corresponding author: arlen@austin.utexas.edu

Article is online at http://www.rnajournal.org/cgi/doi/10.1261/rna.066373. 118. will use the term SSU processome to avoid confusion with related particles that contain intact $35 \mathrm{~S}$ pre-rRNA. Recent highresolution cryo-electron microscopy reconstructions of the SSU processome from S. cerevisiae and the thermophilic fungus Chaetomium thermophilum reveal a splayed-open structure of the rRNA compared to the mature 40S (Kornprobst et al. 2016; Barandun et al. 2017; Chaker-Margot et al. 2017; Cheng et al. 2017; Sun et al. 2017). The SSU processome may represent a metastable intermediate of assembly, as particles with similar structure and composition have been purified from cells under various conditions including stationary phase in which ribosome biogenesis is largely repressed (Barandun et al. 2017; Chaker-Margot et al. 2017).

Progression of the SSU processome to the pre-40S particle requires endonucleolytic cleavages at sites $A_{0}$ and $A_{1}$ within the $5^{\prime}$-ETS to generate the mature $5^{\prime}$-end of $18 S$ and cleavage at site $\mathrm{A}_{2}$ within ITS1 (Woolford and Baserga 2013; Barandun et al. 2018). This transition results in the release of most SSU processome factors, and concomitant large-scale rearrangements of the RNA as the splayed-open structure collapses into the more compact structure of the small subunit (Heuer et al. 2017; Johnson et al. 2017). The cleavage at the $\mathrm{A}_{0}$ site liberates the $5^{\prime}$-ETS for exonucleolytic degradation from its $3^{\prime}$-end by the nuclear RNA exosome (Thoms et al.

(C) 2018 Black et al. This article is distributed exclusively by the RNA Society for the first 12 months after the full-issue publication date (see http:// rnajournal.cshlp.org/site/misc/terms.xhtml). After 12 months, it is available under a Creative Commons License (Attribution-NonCommercial 4.0 International), as described at http://creativecommons.org/licenses/by-nc/4.0/. 
2015). What triggers these rRNA processing events and the subsequent transition of the SSU processome to a pre-40S is not yet known.

A primary feature of the SSU processome is the U3 snoRNA $(S N R 17 A / B)$ which hybridizes to multiple regions of the $5^{\prime}$-ETS as well as $18 \mathrm{~S}$ rRNA to provide a scaffold for the initial folding of the preribosomal RNA and assembly of the domains of the small subunit (Dragon et al. 2002; Dutca et al. 2011). Importantly, U3 hybridizes to residues in the $5^{\prime}$-end of $18 \mathrm{~S}$ that are involved in intramolecular base-pairing required to form the central pseudoknot, a critical RNA element that coordinates all domains of the small subunit (Barandun et al. 2017; Cheng et al. 2017; Sun et al. 2017). Consequently, U3 must be released to allow assembly of the central pseudoknot, and it is likely that the release of $\mathrm{U} 3$ is a principal driver of the RNA rearrangements that promote the transition from the SSU processome to the pre-40S particle. We previously provided evidence that the release of $\mathrm{U} 3$ is driven by the DEAH-box RNA helicase Dhr1 (Ecm16) (Sardana et al. 2015) whose stable association and subsequent activation depends upon direct interactions with the SSU processome factor Utp14 (Zhu et al. 2016). However, how the timing of Dhr1 activation by Utp14 is controlled is not known. Utp14 joins at a late stage of SSU processome assembly, after the majority of the 3'-minor domain has been transcribed (Chaker-Margot et al. 2015; Zhang et al. 2016). Unlike the majority of SSU processome factors, Utp14 remains associated with $20 \mathrm{~S}$ rRNA (Sardana et al. 2013; Zhu et al. 2016) suggesting that it remains on the preribosome during the transition from SSU processome to pre-40S particle, however it is not present on cytoplasmic particles (Heuer et al. 2017; Johnson et al. 2017). Utp14 is a highly-conserved protein found throughout eukaryotes but contains no recognizable domains, and its interaction with the preribosome has only recently begun to be revealed (Sardana et al. 2013; Zhu et al. 2016; Barandun et al. 2017; Cheng et al. 2017).

We sought to further characterize the interaction of Utp14 with the preribosome to understand how it regulates Dhr1 activity in the context of the SSU processome. Here, we used UV Crosslinking and Analysis of cDNA (CRAC) to identify the RNA binding sites of Utp14 and yeast 2-hybrid analysis to map domain interactions with assembly factors and small subunit r-proteins. In addition, we examined the protein and RNA composition of particles arrested with several Utp14 mutants. Our work is consistent with and extends recent structural and genetic analyses of the SSU processome.

\section{RESULTS}

\section{Utp14 binds multiple RNA elements in the SSU processome}

To determine the RNA binding sites of Utp14 we used a modified UV cross-linking and analysis of cDNA (CRAC) protocol (Granneman et al. 2009). UV irradiation induces covalent cross-links between amino acids and neighboring nucleic acids allowing for nucleotide-resolution of RNA binding sites of proteins. The C-terminal His6-tobacco etch virus (TEV) protease recognition site-protein A (HTP) tag was integrated into the genomic locus of UTP14. The HTP tag had no apparent effect on growth (data not shown). Cells were subjected to UV irradiation and RNAs crosslinked to Utp14-HTP were first affinity-purified via the protein A tag under native conditions followed by RNase treatment and a second step purification via its His6 tag under denaturing conditions. To verify that RNAs were crosslinked to Utp14, copurifying RNAs were radio-labeled with ${ }^{32} \mathrm{P}$, separated by SDS-PAGE and autoradiographed (Fig. 1A). The HTP-tagged sample contained a high molecular weight radiolabeled band that was not present in the untagged control. This species was excised, crosslinked RNAs were released from Utp14 by proteinase $\mathrm{K}$ digestion, and the crosslinked RNAs were sequenced following library preparation (see Materials and Methods). Whereas the CRAC protocol involves ligation of oligonucleotides to both ends of the RNA followed by reverse transcription and amplification, we ligated a single oligonucleotide to the $3^{\prime}$-ends of the RNAs, followed by reverse transcription, circularization of the resulting product and amplification. In this strategy we captured reverse transcriptase termination events at RNA-amino acid crosslinks as well as read through events that contain mutations resulting from misincorporation at the crosslinks. Sequence reads from this protocol display a characteristic drop off of reverse transcription reads whose $3^{\prime}$-ends correlate to positions of mutations.

Utp14-HTP crosslinked RNAs were enriched for rRNA and snoRNAs compared to the mock in both replicates (Fig. 1B). Despite the lower level of rRNA enrichment in the second replicate, both data sets showed specific hits within rRNA, mapping primarily to pre-18S rRNA within $35 \mathrm{~S}$ pre-rRNA (Fig. 1C,D; bottom). Utp14 crosslinked to multiple RNA elements within the pre-18S rRNA (Fig. 1C,D; top). The highest read densities corresponded to nucleotides spanning helix 26es7 (hereafter referred to as helix 26) and across the $3^{\prime}$-end of helix 45 through the D-site (helix 45/D-site), which generates the $3^{\prime}$-end of $18 \mathrm{~S}$ after cleavage in the cytoplasm. Consistent Utp14-specific reads were also obtained at helices 18 and 36/37, while read densities across 21es6d (hereafter referred to as ES6) were reproducible but more variable between the two data sets. A small subset of reads aligned to nucleotides surrounding $\sim 480-600$ of the $5^{\prime}$-ETS and the $5^{\prime}$-end of 18S. Mapping these binding sites to a current SSU processome structure (Fig. 1E) showed that helix 26 and helix 45 are $\sim 60 \AA$ apart from one another, while helix 18 is tucked within the core of the structure, and the $5^{\prime}$-ETS sites are on the exterior of the particle $\sim 70 \AA$ away from helix 26 and $\sim 140 \AA$ away from helix 45 . Helices 21 es $6 \mathrm{~d}, 36$, and 37 of the 18S rRNA were unresolved in this structure. These results imply that Utp14 traverses a large area of the SSU processome. It is also possible that these additional sites represent contacts that Utp14 makes at different stages of $40 \mathrm{~S}$ assembly 


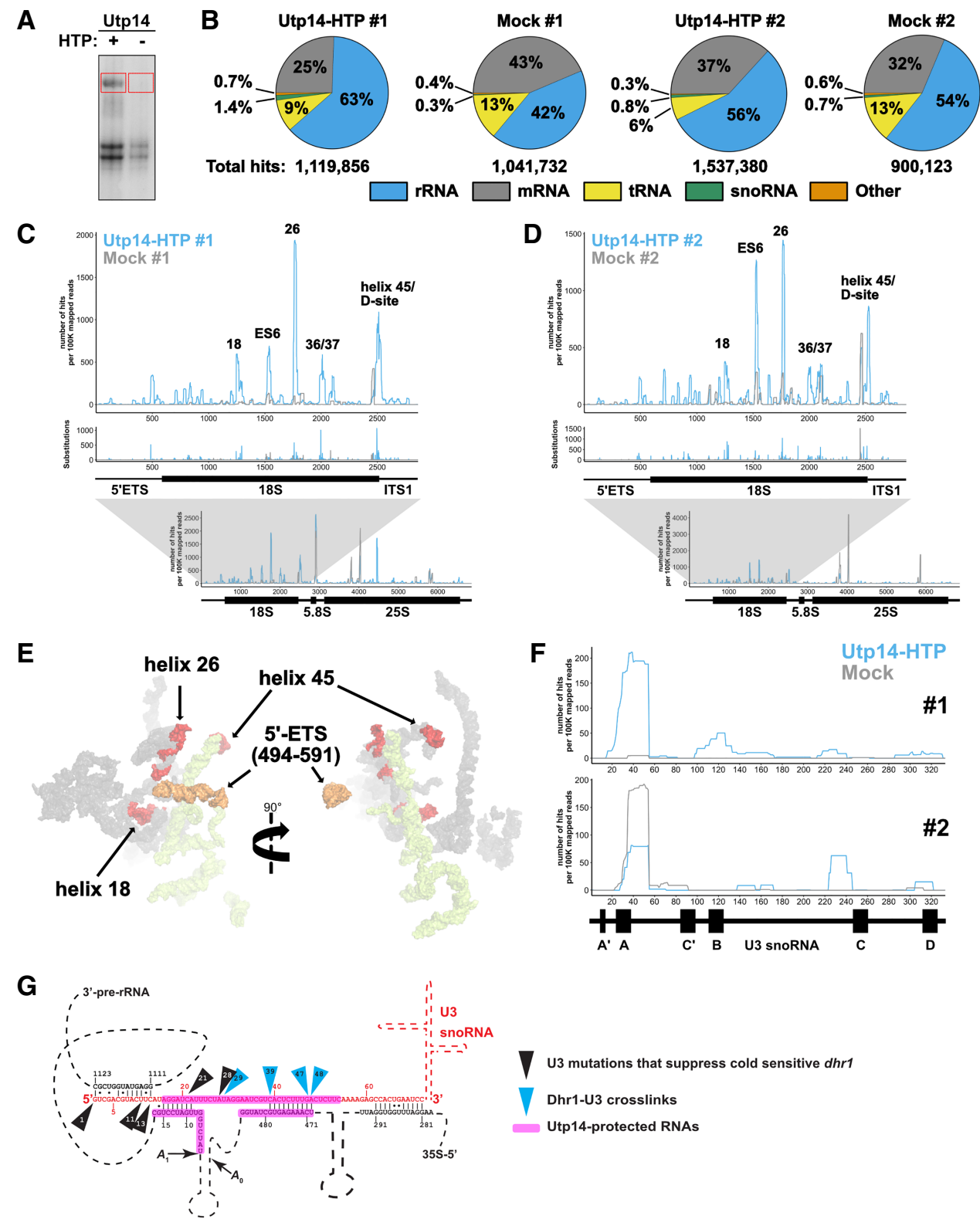

FIGURE 1. Utp14 crosslinks to multiple regions within the pre-18S rRNA. (A) A representative autoradiograph of ${ }^{32} \mathrm{P}$-labeled RNAs crosslinked to Utp14-HTP (+, AJY4051) and mock (-, BY4741). Red boxes indicate the regions of the membrane that were excised and used in library preparation. (B) Percentages of RNA composition grouped by class are shown for both CRAC replicates. Total aligned reads corresponding to each sample are shown below. $(C, D)$ The number of hits per 100K mapped reads (top) and substitutions (middle) are shown against nucleotide position within the pre-18S rRNA (RDN18-1). The number of reads against nucleotide position within the 35S pre-rRNA (RDN37-1) are shown below. Utp14-HTP is shown in light blue, and the mock is shown as gray. Two independent biological replicates are shown. (E) Utp14 crosslinks within 18S rRNA (red) and 5'-ETS (orange) mapped to a recent structure of the SSU processome. RNAs that were not crosslinked with Utp14 are shown in surface representation for $18 \mathrm{~S}$ rRNA (gray) and $5^{\prime}$-ETS (yellow) (PDB: 5WYJ). $(F)$ The number of hits per 100K mapped reads against nucleotide position within U3 (snR17A) for data sets \#1 (top) and \#2 (bottom). A diagram of U3 is shown below the plots. (G) A cartoon of U3 hybridization to the rRNA within the SSU processome displaying Dhr1 crosslinks (blue triangles) and mutations of U3 that suppress a cold-sensitive Dhr1 mutant (black triangles) (Sardana et al. 2015) in relation to Utp14 crosslinks to U3 and the rRNA (magenta highlights). Relevant data processed using pyCRAC are reported in Supplemental File 1.

as Utp14 associates with both the SSU processome and pre$40 \mathrm{~S}$ (Zhu et al. 2016) or could be spurious hits.

Our result that Utp14 crosslinked across the $A_{1}$ site and $5^{\prime}$-ETS is consistent with recent structures of the SSU processome in which limited regions of Utp14 were resolved
(Barandun et al. 2017). That work showed that residues 845-849 of Utp14 contact the $A_{1}$ site and residues 828-834 of Utp14 contact several nucleotides of helix $\mathrm{V}$ of the 5'-ETS, while residues 317-408 and 876-896 of Utp14 wrap around helices VII and VIII of the $5^{\prime}$-ETS. A similar 
interaction of Utp14 with the $5^{\prime}$-ETS is also observed in the SSU processome from the thermophilic fungus $C$. thermophilum (Cheng et al. 2017).

Since Utp14-HTP also enriched for snoRNAs (Fig. 1B), we analyzed the percentage of reads aligning to each snoRNA relative to the total sense aligned reads (Supplemental File 1). U3 snoRNA $(S N R 17 A / B)$ was present in both data sets with the majority of the reads mapping to nucleotides 20-60 of U3 (Fig. 1F). Interestingly, this binding site overlaps the binding site of Dhr1 on U3 that we previously identified (Fig. 1E; Sardana et al. 2015). Although the negative control from data set 2 also contained reads to this region of $\mathrm{U} 3, \mathrm{a}$ recent SSU processome structure confirmed that Utp14 appears to contact U24 and G37 of U3 (Barandun et al. 2017) which are within the range protected by Utp14 in our crosslinking analysis (Fig. 1F). Thus, in addition to its rRNA contacts, we conclude that Utp14 also directly interacts with the U3 snoRNA. Moreover, a small set of reads aligned to snR30. It was previously reported that snR30 hybridizes to helix 26, a major crosslink site of Utp14, before its release by Rok1 (Martin et al. 2014). Thus, the reads mapping to snR30 may reflect a transient interaction between Utp14 and snR30. When taken together, these data demonstrate that Utp14 is an RNA binding protein that contacts multiple RNA elements within the SSU processome with its primary sites being helix 26 and helix 45/D-site.
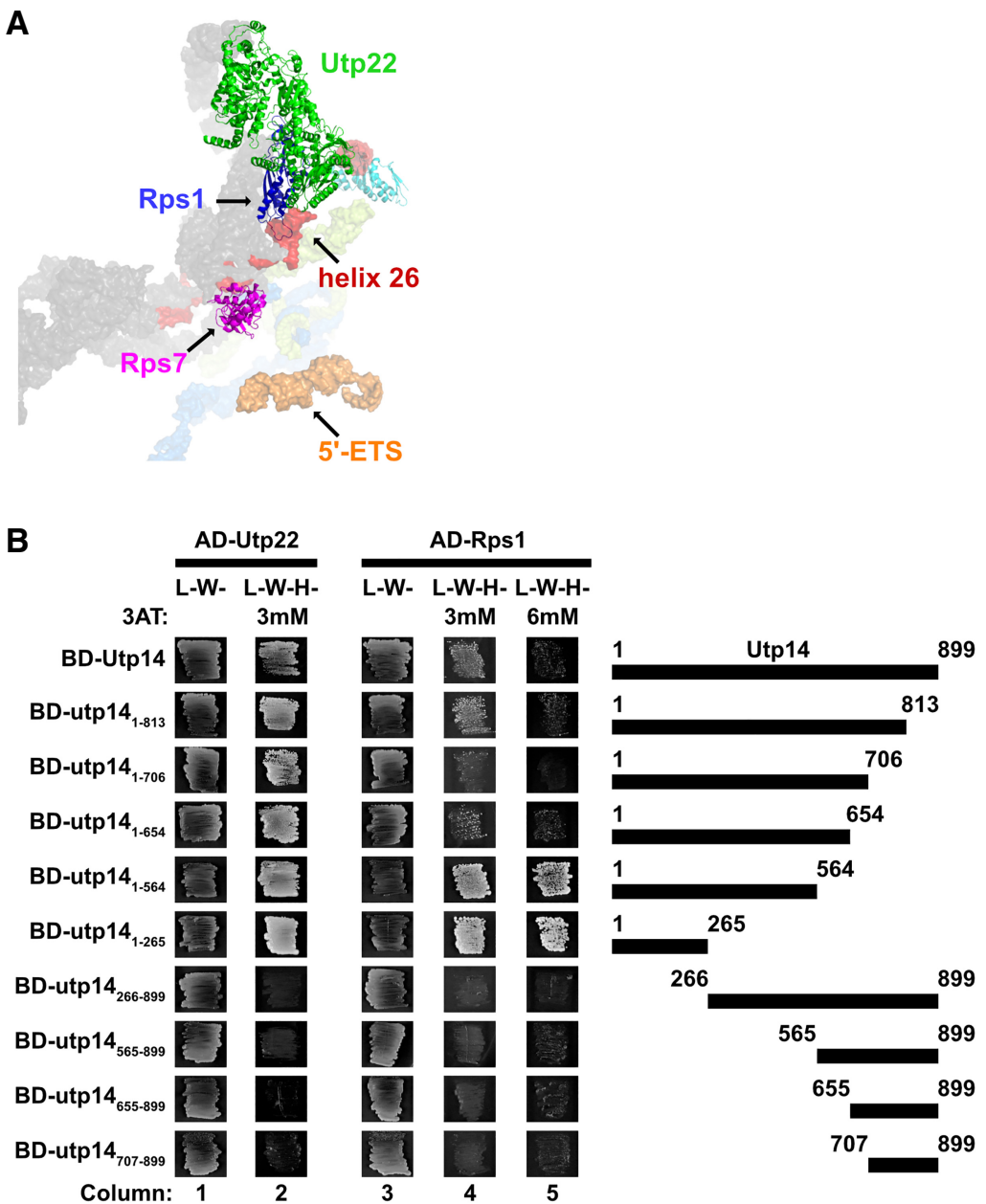

FIGURE 2. Residues 1-265 of Utp14 interact with proteins associated with helix 26. (A) Proteins that bind near Utp14 crosslinking sites in the SSU processome (PDB: 5WYJ). Utp22 (green), Rps1 (blue), and Rps7 (magenta) are shown. Pnol (cyan) is also shown for perspective. Utp14 crosslinking sites are shown in red (18S rRNA) and orange (5'-ETS). 18S rRNA (gray), 5' -ETS (yellow), and U3 (light blue) are shown in surface representations. (B) Yeast two-hybrid interaction data between Utp14 and Utp22 and Utp14 and Rps1 are shown. Strains carrying the indicated constructs were patched onto $\mathrm{Leu}^{-} \operatorname{Trp}^{-}\left(\mathrm{L}^{-} \mathrm{W}^{-}\right)$and $\mathrm{Leu}^{-} \operatorname{Trp}^{-} \mathrm{His}^{-}\left(\mathrm{L}^{-} \mathrm{W}^{-} \mathrm{H}^{-}\right)$media supplemented with 3-Amino-1,2,4-triazole (3AT) as indicated (BD, GAL4BD; AD, GAL4AD). A cartoon of the Utp14 constructs indicating amino acid positions is shown to the right.

\section{The $\mathrm{N}$ terminus of Utp14 interacts with proteins that bind Helix 26}

We first attempted to support our crosslinking result that Utp14 binds to helix 26 using the yeast three-hybrid system, but we were unable to detect a specific interaction (data not shown). As an alternative approach, we reasoned that Utp14 may interact with proteins in the vicinity of its RNA binding sites. Utp22, Rrp7, and Rps1 (eS1) are within close proximity of helix 26 in recently solved structures of the SSU processome (Fig. 2A; Cheng et al. 2017; Sun et al. 2017). Utp22 and Rrp7 are components of the UTPC subcomplex that are recruited to the preribosome after synthesis of the central domain of 18S, and Rrp7 makes direct contacts with helix 26 (Lin et al. 2013; Chaker-Margot et al. 2015; Zhang et al.
2016). Additionally, an interaction between Utp22 and Utp14 was recently reported in two large-scale yeast two hybrid $(\mathrm{Y} 2 \mathrm{H})$ analyses of ribosome biogenesis factors (Baßler et al. 2016; Vincent et al. 2018). Rps1 is an r-protein needed upstream of processing at $A_{0}, A_{1}, A_{2}$, and $D$ (Ferreira-Cerca et al. 2005), and remains bound to helix 26 in the mature 40S (Ben-Shem et al. 2011).

We used $\mathrm{Y} 2 \mathrm{H}$ analysis to test direct interactions between Utp14 and these proteins. Indeed, full length Utp14 interacted with Utp22 and Rps1 as indicated by growth on reporter media containing 3-amino-1,2,4-triazole (3AT), a competitive inhibitor of the HIS3 gene product that increases the stringency of the assay. (Fig. 2B; see columns 2 and 4). Utp14 is 899 amino acids in length, and much of the protein is not 
A

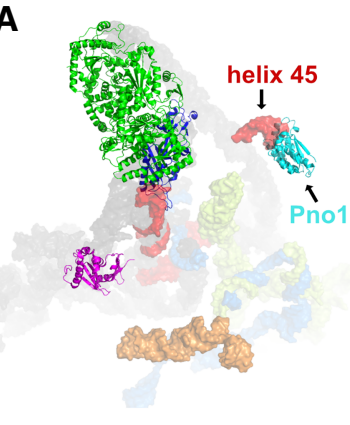

B

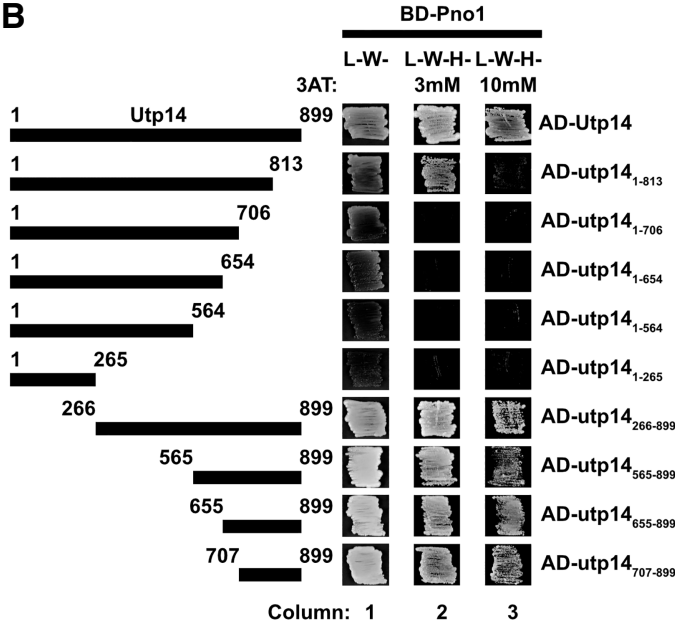

Column:

2

FIGURE 3. Residues 707-813 of Utp14 interact with Pno1. (A) Proteins that bind in the vicinity of the Utp14 crosslinking sites in the SSU processome (PDB: 5WYJ). Coloring is the same as in Figure 2A. (B) Yeast two-hybrid interaction data between Utp14 fragments and Pnol are shown. Strains carrying the indicated constructs were patched onto $\mathrm{Leu}^{-} \mathrm{Trp}^{-}\left(\mathrm{L}^{-} \mathrm{W}^{-}\right)$and $\mathrm{Leu}^{-} \mathrm{Trp}^{-}$ His $^{-}\left(\mathrm{L}^{-} \mathrm{W}^{-} \mathrm{H}^{-}\right)$media supplemented with 3AT. (Abreviations as used in Fig. 2.) A cartoon of the Utp14 constructs indicating amino acid positions is shown to the left.

resolved in recent SSU processome structures. To determine which region of Utp14 interacts with these proteins, we assayed a series of $\mathrm{N}$ - and C-terminal truncations of Utp14 for interaction. All C-terminal truncations retained interaction with Utp22 and Rps1. In contrast, all N-terminal deletions of Utp14 that were tested lost interaction with Utp22 and Rps1. Thus, the N-terminal portion (residues 1-265) of Utp14 was both necessary and sufficient for interaction with Utp22 and Rps1. We did not detect an interaction between Utp14 and Rrp7 (data not shown) and we note that the interaction between Utp14 and Rps1 was enhanced by deletion of aa 565 to 899 (Fig. 2B; cf. columns 4 and 5). Possibly, full length Utp14 folds in a way that inhibits its interaction with Rps1 outside the context of the SSU processome.

The TPR domain repeats of Rrp5 are also in the vicinity of helix 26 (Sun et al. 2017), and an interaction between C. thermophilum Utp14 and Rrp5 was recently reported (Baßler et al. 2016). This observation prompted us to map the interaction interface between these two proteins, however we were unable to detect interactions between any of the S. cerevisiae Utp14 constructs and Rrp5 (data not shown). Taken together, the $\mathrm{Y} 2 \mathrm{H}$ interaction data between Utp22 and Rps1 with Up14 and the UV crosslinking of Utp14 to helix 26 suggests that the $\mathrm{N}$ terminus of Utp14 (residues 1-265) is responsible for its interaction with helix 26.

\section{A C-terminal portion of Utp14 interacts with Pno1}

To support the Utp14 crosslinks mapping across helix 45 and the D-site, we first tested the interaction between Utp14 and this region of RNA by yeast three-hybrid but were unable to detect an interaction (data not shown). Consequently, we again considered that Utp14 may interact with proteins in the vicinity of helix 45 and the D-site. Recent structures of the SSU processome show that Pno1 (Dim2) binds helix 45 (Fig. 3A; Barandun et al. 2017). Pnol is an essential $\mathrm{KH}$-like domain protein that stably associates with the preribosome once the majority of the $3^{\prime}$-minor rRNA domain of $18 \mathrm{~S}$ is synthesized (ChakerMargot et al. 2015; Zhang et al. 2016) and remains on pre-40S particles that enter the cytoplasm (Vanrobays et al. 2004; Heuer et al. 2017; Johnson et al. 2017). Pno1 is thought to recruit the dimethyltransferase Dim1, that methylates the $3^{\prime}$ end of the 18S rRNA (Vanrobays et al. 2004). An interaction between $c t$ Utp14 and $c t$ Pnol was also reported in a largescale screen for interactions among biogenesis factors (Baßler et al. 2016). To define the domain of Utp14 that interacts with Pno1, we again used $\mathrm{Y} 2 \mathrm{H}$ analysis to assay interactions between the various Utp14 fragments and Pnol (Fig. 3B). Due to the proximity of the helix 45 to helix 26 , we initially expected Pno1 to interact with the $\mathrm{N}$ terminus of Utp14. However, we found that $\mathrm{C}$-terminal truncations abolished or weakened the interaction of Utp14 with Pno1, while N-terminal truncations maintained the interaction (Fig. 2C; column 3). Furthermore, the Utp14 fragment containing residues 1-813 maintained an interaction with Pnol on 3 mM 3AT, but not $10 \mathrm{mM} 3 \mathrm{AT}$ (Fig. 3B; column 2) suggesting that residues 707-813 of Utp14 are critical for the interaction with Pno1. Moreover, while this manuscript was in preparation an interaction between $c t \mathrm{Utp} 14$ and the $\mathrm{KH}$-like domain of $c t$ Pnol was reported (Sturm et al. 2017). Taken together, we infer that Utp14 binds to or near helix 45 and the D-site, and that the binding interface required for this interaction is between the KH-like domain of Pnol and residues 707-813 of Utp14.

\section{Utp14- $\Delta C$ copurifies with an extraribosomal subcomplex containing Rps7 and Rps22}

To explore the functional significance of the interactions of the N- and C-terminal regions of Utp14, we used two truncation mutants deleted of residues 1-265 (Utp14- $\Delta \mathrm{N}$ ) or residues 707-899 (Utp14- $\Delta$ C). These Utp14 mutants are expected to lose interactions with proteins and RNA at helix 26 and helix 45/D-site, respectively (Figs. 2, 3). Neither of the truncation mutants was able to complement the loss of Utp14 (Fig. 4A). To rule out the possibility that these mutants were nonfunctional because they failed to express well or engage with preribosomes, we assayed their sedimentation in 


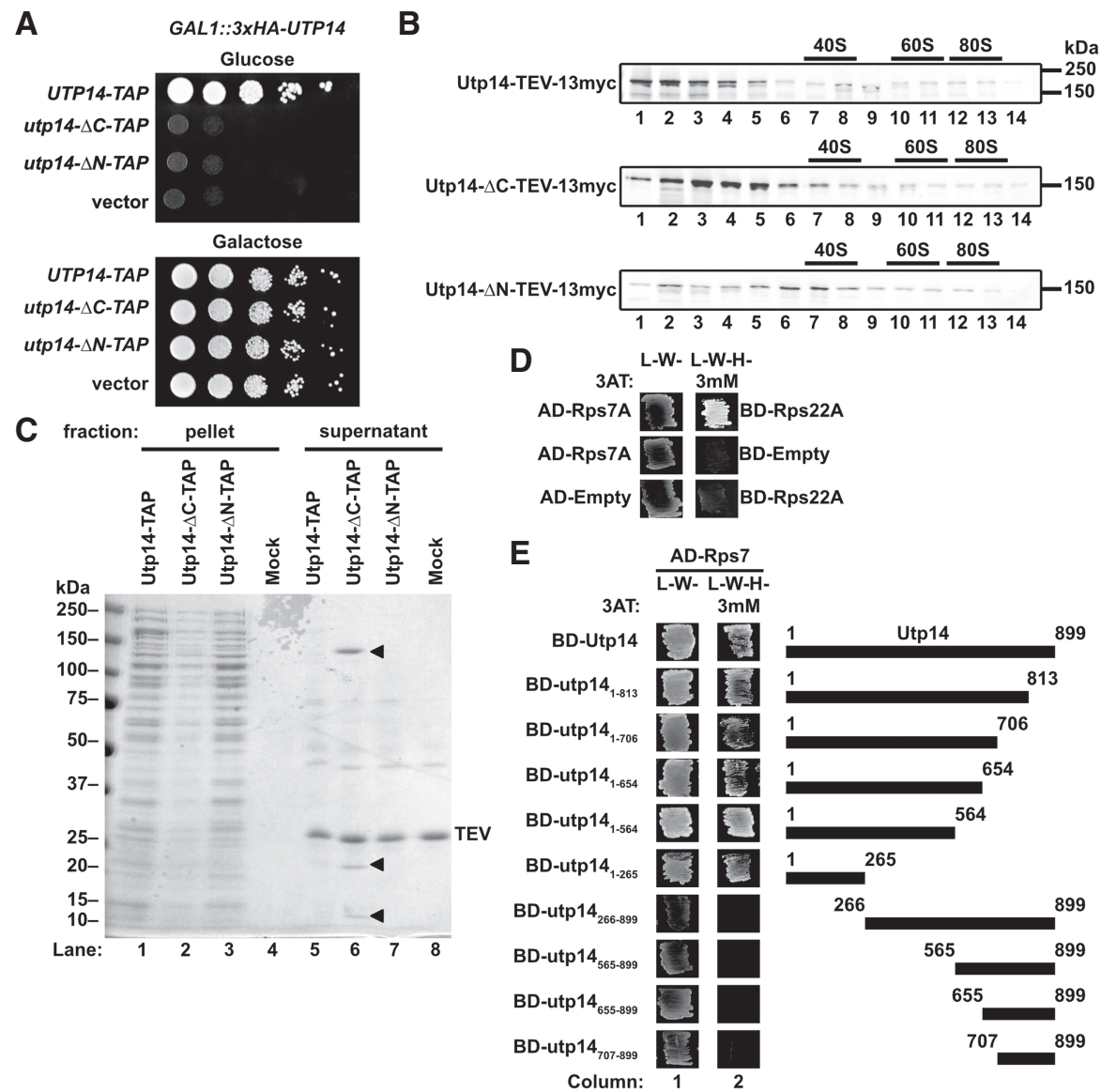

FIGURE 4. The $\mathrm{N}$ terminus of Utp14 interacts with an extraribosomal Rps7-Rps22 heterodimer. (A) Truncations from either termini of Utp14 are unable to support growth as shown by 10-fold serial dilutions of GAL1::3xHA-UTP14 cells (AJY3243) harboring vectors encoding UTP14-TAP (pAJ4176), utp14- $\triangle C-T A P$ (pAJ4177), utp14- $\triangle N-T A P$ (pAJ4178), or empty vector (pRS415) spotted on media lacking leucine containing either galactose or glucose. $(B)$ Western blot analysis of sucrose gradient fractions showing that the different Utp14 truncation mutants sediment into the gradients. $(C)$ Coomassie-stained gel of proteins that copurified with full-length or truncated Utp14 proteins. Pellet and supernatant fractions were separated by overlaying eluate onto sucrose cushions followed by ultracentrifugation. The arrow heads in lane 6 indicate Utp14- $\Delta \mathrm{C}(\sim 150 \mathrm{kDa})$, Rps7 ( $20 \mathrm{kDa})$, and Rps22 ( 10 kDa). (D) Yeast two-hybrid interaction data for Rps7 and Rps22. (E) Yeast two-hybrid interaction between Utp14 and Rps7 are shown. A cartoon of the Utp14 constructs is shown to the right. (Abbreviations as in legend of Figure 2.)

sucrose gradients. Both the $\mathrm{N}$ - and C-terminally truncated proteins showed a population of protein that cosedimented in the $40 \mathrm{~S}$ to $80 \mathrm{~S}$ region of the gradient, similar to wildtype, suggesting that both proteins enter into preribosomal particles (Fig. 4B). However, less Utp14- $\Delta \mathrm{C}$ sedimented in these deeper gradient fractions than Utp14- $\Delta \mathrm{N}$ did, suggesting that the association of Utp14- $\Delta \mathrm{C}$ with preribosomes is reduced.

We then performed affinity-purifications of C-terminally tandem affinity purification (TAP) tagged Utp14 constructs. Our purification strategy for preribosomal particles involved sedimentation of particles through a sucrose cushion to separate bait associated with preribosomes from extraribosomal bait and other nonribosome-bound proteins. We noted two lower molecular weight species present in the Utp14- $\Delta \mathrm{C}$ TAP extraribosomal fraction (Fig. 4C; lane 6) that were not present in the full length Utp14 or Utp14- $\Delta \mathrm{N}$ purifications. Mass spectrometry identified the $\sim 20 \mathrm{kDa}$ species to be
Rps7 (eS7) and the $10 \mathrm{kDa}$ species to be Rps22 (uS8). Rps7 and Rps22 interact directly with one another in the context of nascent and mature ribosomes (Ben-Shem et al. 2011; Barandun et al. 2017; Cheng et al. 2017; Sun et al. 2017) and we recapitulated this interaction by $\mathrm{Y} 2 \mathrm{H}$ (Fig. 4D). We then used the $\mathrm{Y} 2 \mathrm{H}$ system to ask if Utp14 interacted with either Rps7 or Rps22. We found that the $\mathrm{N}$ terminus of Utp14 (residues 1-265) was both necessary and sufficient for interaction with Rps7 (Fig. 4E). We did not, however, detect an interaction between Utp14 and Rps22 (data not shown). We considered the possibility that Rps7 or Rps22 is needed for the recruitment of Utp14 to the SSU processome but did not observe any decreased association of Utp14 upon depletion of either Rps7 or Rps22 in sucrose sedimentation assays (data not shown). These results suggest that Rps7 and Rps22 initially bind to the SSU processome in an unstable fashion and require full length Utp14 to stabilize their interaction with the SSU processome. 


\section{Protein composition of wild-type and mutant Utp14 particles}

Because our data suggest that Utp14 interacts with multiple proteins and RNA elements of the SSU processome, we sought to further understand how the presence of Utp14 affects the protein composition of preribosomal particles. We previously showed that Utp14 interacts with and activates the RNA helicase Dhr1 (Zhu et al. 2016). Both proteins are recruited to the preribosome at a similar stage of maturation, (Chaker-Margot et al. 2015; Zhang et al. 2016) and thus are expected to stall progression of the SSU processome at a similar point. To ask if Utp14 is required for the recruitment or stability of additional proteins, we compared the protein composition of wildtype particles to particles depleted of Utp14 or Dhr1. We isolated preribosomal particles from cultures expressing C-terminally TAP-tagged Enp1 after the repression of transcription of UTP14 or DHR1 and depletion of the respective proteins. Enp1 is an ideal bait for this assay as it binds prior to Utp14 association with preribosomes (Zhang et al. 2016) and remains associated with pre-40S particles until the cytoplasm (Johnson et al. 2017), after Utp14 has been released. After affinity-purification and TEV elution, we sedimented samples through sucrose cushions to separate preribosomal particles from extraribosomal bait and other copurifying extraribosomal proteins. Following mass spectrometry, we generated relative spectral abundance factor (RSAF) values as described previously (Sardana et al. 2015). Figure 5A shows a heat map of RSAF values for $40 \mathrm{~S}$ biogenesis factors that copurified with the Enp1-TAP particles, normalized to the mean RSAF value for the UTP-B subcomplex of the sample as done previously (Zhang et al. 2016). This semiquantitative analysis reflected the relative stoichiometry of proteins within the purified particles, validated by the twofold abundance of factors known to be present as dimers (Emg1 and Kre33) or in a 2:1 stoichiometry (Nop1 and Snu13) (Barandun et al. 2017; Cheng et al. 2017; Sun et al. 2017).

As expected, the Utp14- and Dhr1-depleted particles showed significantly reduced signal for Utp14 and Dhr1,
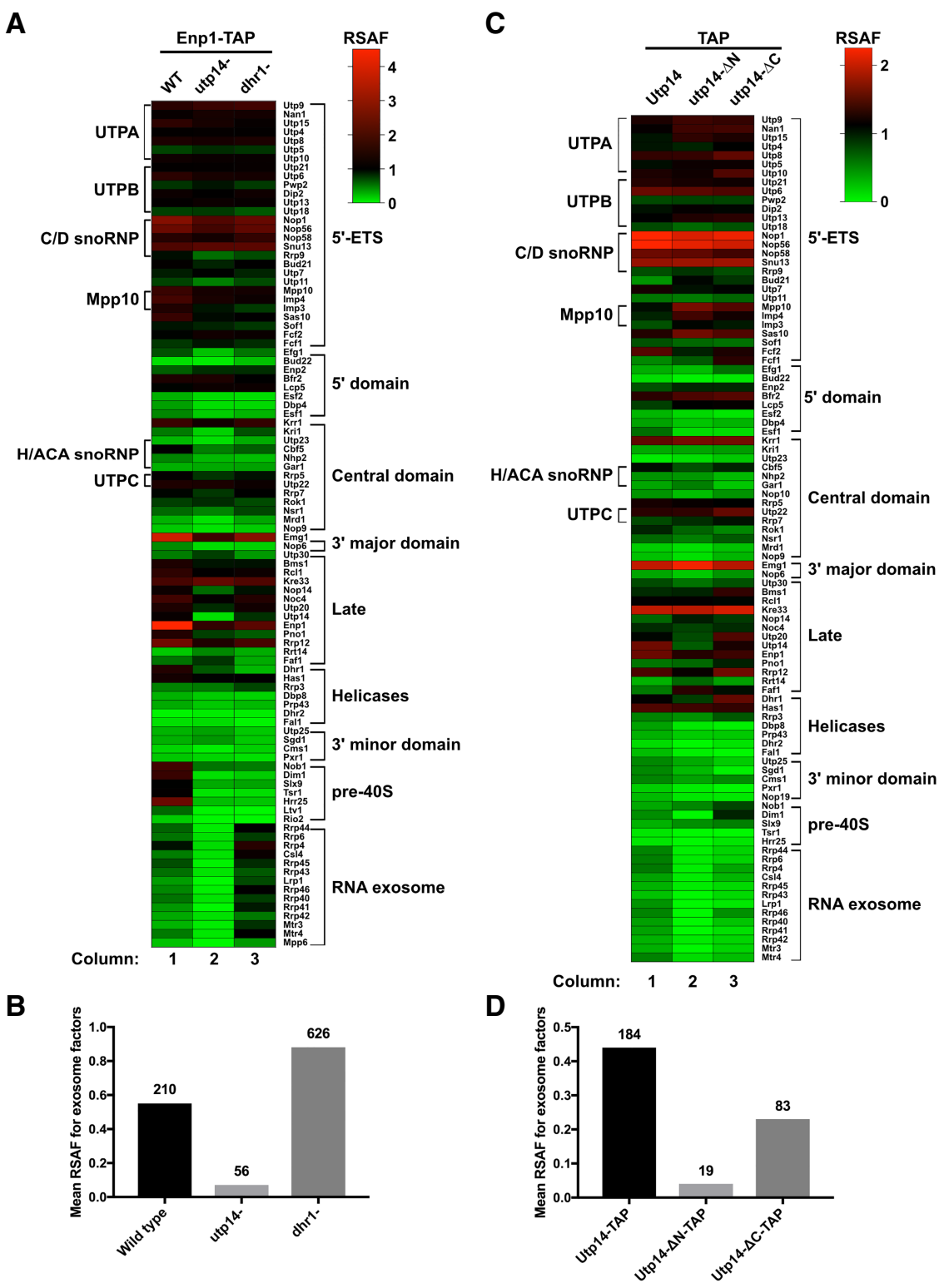

FIGURE 5. Proteomic profiles of mutant Utp14 particles. (A) A heatmap representing the RSAF of each assembly factor identified by mass spectrometry relative to the mean RSAF of the UTP-B subcomplex of each sample for the affinity-purifications of wild-type, Utp14-depleted, or Dhr1depleted particles purified via Enp1-TAP. $(B)$ A histogram comparing the mean RSAF values (normalized to UTP-B) for the exosome for wild-type, Utp14-depleted, or Dhr1-depleted particles purified via Enp1-TAP. The total sum of spectral counts for the exosome factors in each sample is listed above each bar. $(C)$ A heatmap and $(D)$ a histogram representing data processed in the same manner as $A$ and $B$, respectively, but particles purified via TAP-tagged WT or truncated Utp14. Coloring for the heatmaps reflects apparent stoichiometry of each factor: green, RSAF values less than one; black, RSAF value of approximately one; and red, RSAF of approximately two or greater. Proteins are grouped according to their order of recruitment to the preribosome as reported in Zhang et al. (2016) or by function. Heatmaps were generated in Graphpad Prism version 7.0c.169 for Mac iOS (www.graphpad.com). Complete data for this figure are provided in Supplemental File 2.

respectively. The overall compositions of the Utp14- and Dhr1-depleted particles revealed similar levels of SSU processome factors (Fig. 5A; Supplemental File 2) while the wild-type Enp1 particles appeared to contain more pre-40S than either the Utp14- or Dhr1-depleted particles. This 
observation is consistent with the notion that Utp14 and Dhrl are both needed for the transition from the SSU processome to the pre-40S and that in their absence, Enp1 accumulates in the SSU processome. We note several other differences among the particles after applying the criteria that a given factor in the truncated Utp14 particles showed a $\log _{2}$-fold change of \pm 1 or more relative to the Dhr1-depleted particles, and at least one of the samples contained at least five spectral counts. The most notable difference among these particles was a strong reduction of factors belonging to the RNA exosome in the Utp14-depleted particle relative to the wild-type and Dhr1-depleted particles (Fig. 5A,B) suggesting that Utp14 depletion stalls the assembly of the SSU processome prior to the recruitment of the exosome.

As a complementary approach, we next asked if there were any changes in the protein composition of the truncated Utp14 mutant particles compared to full length Utp14. To do this we affinity-purified particles via the C-terminal TAP-tagged wild-type and truncated Utp14 constructs (Fig. 4C). The particles affinity-purified by wild-type or truncated Utp14 displayed overall similar protein compositions, but with some differences (Fig. 5C; Supplemental File 2). Most notably, the full-length Utp14 particles contained the exosome, while it was nearly absent from the Utp $14-\Delta \mathrm{N}$, and significantly reduced in the Utp14- $\Delta \mathrm{C}$ particle (Fig. 5D). Moreover, the Utp14- $\Delta$ C particles were enriched for Nob1 and slightly enriched for Dim1 and its interacting partner Pno1. Conversely, the Utp14- $\Delta$ N particles completely lacked Dim1 but contained wild-type levels both of Nob1 and Pno1. In general, the Utp14- $\Delta \mathrm{C}$ particles contained a greater abundance of pre-40S factors than the full-length Utp14 or Utp14$\Delta \mathrm{N}$ particles. These observations support the notion that the Utp14- $\Delta \mathrm{N}$ particle is stalled in the SSU processome assembly pathway upstream of the Utp14- $\Delta \mathrm{C}$ particle. Furthermore, both mutant particles displayed overall reduced signal relative to the full length Utp14 particles for the RNA helicase Dbp8 and its cofactor Esf2 and overall decrease in $3^{\prime}$ minor domain factors Utp25 and Sgd1 suggesting that the Utp14 mutants stalled biogenesis prior to their recruitment or after their release. The primary conclusion from our proteomic analysis is that Utp14 appears to be required for the efficient recruitment of the exosome.

\section{RNA composition of wild-type and mutant Utp14 particles}

We next asked whether the Utp14 mutant particles also differed in their content of rRNA processing intermediates. RNA was prepared from TAP-tagged wild-type and Utp14 mutant particles and analyzed by northern blotting to detect rRNA processing intermediates (Fig. 6A). Wild-type and truncated mutant Utp14 associated with distinct rRNA processing intermediates consistent with their ability to bind preribosomal particles (Fig. 6B). Particles pulled down with full-length Utp14 contained 35S, 33S, 23S, 22/21S, and 20S
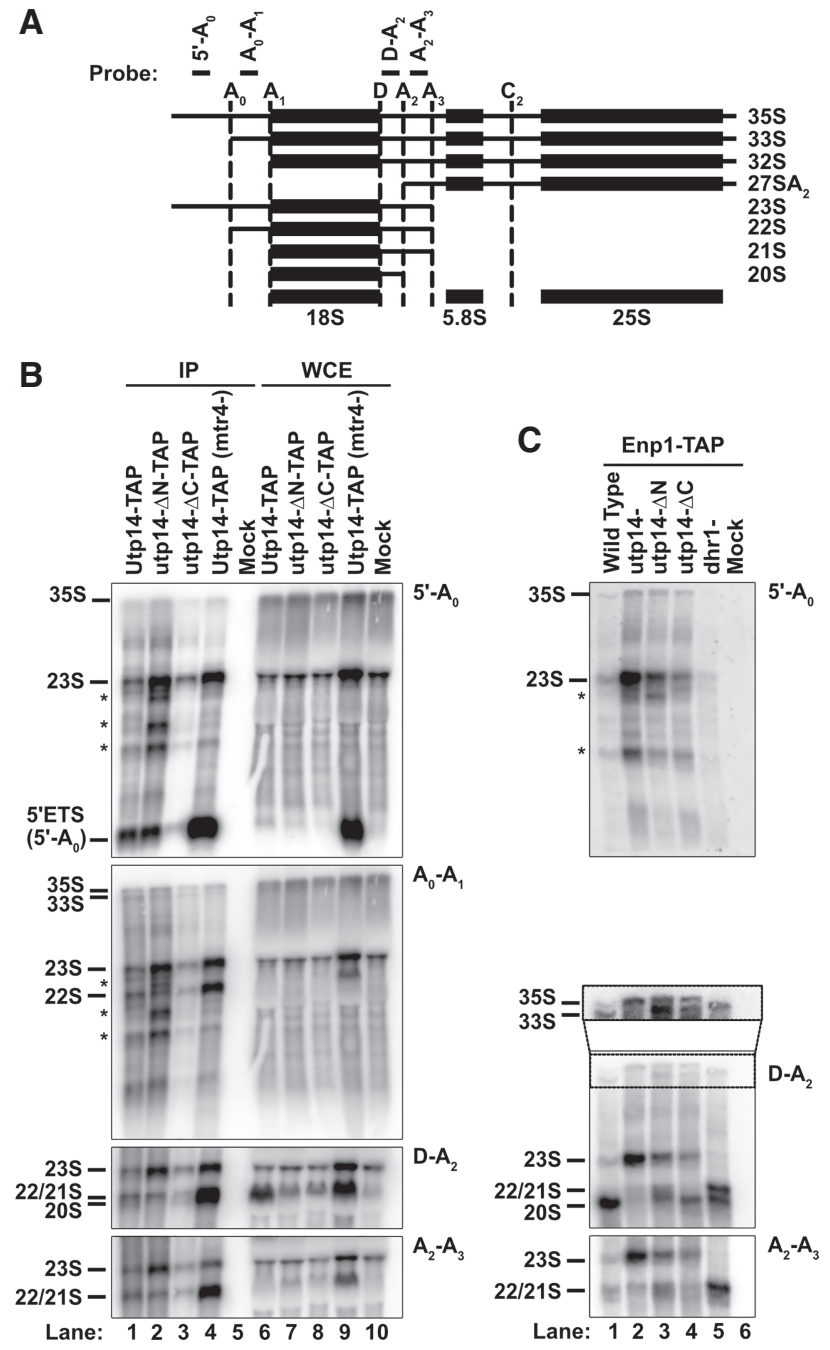

FIGURE 6. The rRNA processing intermediates associated with mutant Utp14 particles. (A) A cartoon of rRNA processing and oligos used to detect intermediates. The sequences for the probes are: $5^{\prime}-\mathrm{A}_{0}\left(5^{\prime}-\mathrm{GGT}\right.$ CTCTCTGCTGCCGGAAATG- $\left.3^{\prime}\right), \mathrm{A}_{0}-\mathrm{A}_{1}$ (5'-CCCACCTATTCCCTC TTGC-3'), D-A ( $_{2}$ '-TCTTGCCCAGTAAAAGCTCTCATGC-3'), $\mathrm{A}_{2}-$ $\mathrm{A}_{3}$ (5'-TGTTACCTCTGGGCCCCGATTG-3'). $(B, C)$ Northern blots for rRNA processing intermediates affinity-purified via $(B)$ TAP-tagged Utp14 full length and truncation mutants or untagged wild-type (mock) and $(C)$ TAP-tagged Enp1 from cells depleted of Utp14 or Dhr1, conditionally expressing Utp14 truncation mutants or from untagged Enp1 (mock). Images were captured on a Typhoon FLA9500 and processed in ImageJ.

rRNA intermediates (Fig. 6B; lane 1), reflecting its association with the SSU processome and pre-40S at multiple stages of pre-rRNA processing. Utp14- $\Delta \mathrm{N}$ associated with $35 \mathrm{~S}, 33 \mathrm{~S}$, 23S, and 22/21S, but not 20S (Fig. 6B; lane 2, D-A panel). Similar to full length Utp14, the Utp14- $\Delta$ C mutant associated with 35S, 33S, 23S, 22/21S, and 20S (Fig. 6B; lane 3), but copurified with less rRNA overall, consistent with its decreased association with the preribosome (Fig. 5A). The lack of $20 \mathrm{~S}$ rRNA in the Utp14- $\Delta \mathrm{N}$ particle, indicates that this particle is stalled earlier in the processing pathway, at $\mathrm{A}_{2}$ cleavage, compared to the Utp14- $\Delta \mathrm{C}$ mutant particle. This result 
agrees with the proteomic profiles described above, in which the Utp14- $\Delta \mathrm{N}$ contained overall fewer pre-40S factors than the Utp14- $\Delta$ C (Fig. $4 \mathrm{~A}$ ).

The exosome is required for the exonucleolytic degradation of the $5^{\prime}-\mathrm{A}_{0}$ fragment (Thoms et al. 2015). Because the mutant Utp14 particles were deficient for the exosome (Fig. 4A), we asked if the $5^{\prime}-\mathrm{A}_{0}$ fragment was enriched in the Utp14 mutant particles. For comparison, we depleted the exosome-associated helicase Mtr4 (Fig. 6B; lane 4) to inhibit degradation of the $5^{\prime}-\mathrm{A}_{0}$ fragment (Thoms et al. 2015). The Mtr4-depleted sample was highly enriched for the $5^{\prime}-\mathrm{A}_{0}$ fragment, as expected. However, the Utp14 mutant particles did not show a similar enrichment for this fragment despite being severely depleted for the exosome (Fig. 4B), suggesting that the apparent lack of exosome recruitment in the Utp14 mutant particles does not result in a noticeable defect in degradation of $5^{\prime}-\mathrm{A}_{0}$ in these particles. For the Utp14- $\Delta \mathrm{N}$ mutant, this discrepancy could explained if the RNA of the stalled particle was not cleaved at $\mathrm{A}_{0}$ and instead subjected to $3^{\prime}$-exonucleolytic degradation by the exosome and/or endonucleolytic cleavage by Utp24 at the recently identified Q site (Choque et al. 2018). The accumulation of apparent degradation intermediates in this particle (Fig. 6B; asterisks) is consistent with this scenario.

As an alternative method to ask how the Utp14 mutants affected rRNA processing, we carried out a second set of purifications using Enp1-TAP from cells expressing wild-type Utp14, the $\mathrm{N}$ - and C-terminal truncation mutants or depleted of Utp14. For comparison, we also affinity purified Enp1TAP from Dhr1-depleted cells. Northern blot analysis of the RNAs that copurified with Enp1-TAP from wild-type cells revealed that Enp1 primarily associated with $20 \mathrm{~S}$ but low levels of 33S, 23S, and 22S/21S were also observed (Fig. 6C; lane 1). This result is consistent with the late entry of Enp1 into the SSU processome and its continued association with pre-40S (Chaker-Margot et al. 2015; Zhang et al. 2016; Johnson et al. 2017; Sun et al. 2017). In the absence of Utp14, Enp1-TAP associated primarily with $23 \mathrm{~S}$ (Fig. 6C; lane 2) with a low level of $22 \mathrm{~S} / 21 \mathrm{~S}$ also detected. Interestingly, in the absence of Utp14, Enp1 also associated with low levels of $35 \mathrm{~S}$ but not $33 \mathrm{~S}$ as observed in wild-type cells. Apparently, in the absence of Utp14, cleavage at $\mathrm{A}_{0}$ is blocked and Enp1 is recruited to $35 \mathrm{~S}$ instead of $33 \mathrm{~S}$. The strong accumulation of $23 \mathrm{~S}$ suggests that Utp14 is also required for cleavages at $\mathrm{A}_{1}$ and $A_{2}$. The low level of $22 \mathrm{~S} / 21 \mathrm{~S}$ may be due to continued processing in the presence of residual Utp14 or indicate that Utp14 is not absolutely required for $A_{1}$ and $A_{2}$ cleavage. In addition, depletion of Utp14 resulted in the accumulation of apparent degradation intermediates that were detectable with the $5-\mathrm{A}_{0}$ probe (asterisks in Fig. $6 \mathrm{C}$ ) suggesting that Utp14-depleted particles are also subjected to degradation similar to the Utp14- $\Delta \mathrm{N}$-TAP particles.

The two Utp14 truncation mutants resulted in Enp1 association with RNAs reflecting processing that was intermediate between that of wild-type and Utp14-depleted cells. In the presence of Utp14- $\Delta \mathrm{N}$, Enp1 associated with both $35 \mathrm{~S}$ and $33 \mathrm{~S}$ RNAs, and instead of the strong accumulation of $23 \mathrm{~S}$ in Utp14-depleted cells or 20S in wild-type cells, signal was roughly equally distributed among 23S, 22/21S, and $20 \mathrm{~S}$ species (Fig. 6C; lane 3). In contrast, in the presence of Utp14- $\Delta \mathrm{C}$ Enp1 associated with both $35 \mathrm{~S}$ and $33 \mathrm{~S}$ but the levels of $23 \mathrm{~S}$ and $22 \mathrm{~S} / 21 \mathrm{~S}$ were reduced with $20 \mathrm{~S}$ predominating (Fig. 6C; lane 4). The presence of $20 \mathrm{~S}$ in the Enp1-purified particle from Utp14- $\Delta \mathrm{N}$-expressing cells was surprising given that Utp14- $\Delta \mathrm{N}$ itself does not copurify with $20 \mathrm{~S}$ (Fig. $6 \mathrm{~B}$; lane 2). This may indicate that while Utp $14-\Delta \mathrm{N}$ associates with preribosomes that have not yet been cleaved at $\mathrm{A}_{2}$, it may not stably associate with particles after $\mathrm{A}_{2}$ cleavage. These results indicate that the $\mathrm{N}$ - and $\mathrm{C}$-terminally truncated proteins support rRNA processing that is intermediate between that of wild-type and Utp14-depleted cells, with the Utp14- $\Delta$ C mutant supporting more extensive processing. By comparison, in the absence of Dhr1 Enp1 copurified with 33S, 22/21S, and $20 \mathrm{~S}$ but not $35 \mathrm{~S}$ or $23 \mathrm{~S}$ (Fig. 6C; lane 5), indicating that Utp14 is required upstream of Dhr1 for cleavages at $\mathrm{A}_{0}$ and $A_{1}$. The accumulation of 22/21S rRNA from Utp14$\Delta \mathrm{N}$-expressing cells was similar to the processing defects of the Dhr1-depleted particles, suggesting the Utp14- $\Delta \mathrm{N}$ is defective in its ability to stimulate Dhrl efficiently (Fig. 6C; cf. lanes 3 and 5).

\section{DISCUSSION}

We previously identified Dhrl as the RNA helicase that unwinds U3 from the pre-rRNA (Sardana et al. 2015). Considering the central role that U3 hybridization to the pre-rRNA plays in organizing the structure of the SSU processome, its unwinding by Dhr1 likely contributes to disassembly of the SSU processome in the transition to the pre$40 \mathrm{~S}$ particle. What times the activation of Dhrl, to unwind U3 at the appropriate stage of SSU processome assembly remains an open question. We identified Utp14 as a Dhr1-interacting partner that stimulates the unwinding activity of Dhrl (Zhu et al. 2016), raising the possibility that Utp14 is involved in timing Dhrl activity in vivo. In an effort to understand how Utp14 might coordinate SSU processome assembly with stimulation of Dhrl activity, we mapped the interaction of Utp14 with the preribosome identifying that Utp14 binds to multiple regions within the SSU processome, including $5^{\prime}$, central, and $3^{\prime}$ elements of the pre-18S rRNA and U3. While this manuscript was in preparation, partial structures of Utp14 in the SSU processome were solved (Barandun et al. 2017; Cheng et al. 2017). Our analysis complements these structural analyses by uncovering how unresolved elements of Utp14 interact with the SSU processome (Fig. 7A). Moreover, our analysis suggests a model in which Utp14 is poised to communicate between the $5^{\prime}$ - and $3^{\prime}$-ends of pre-18S rRNA to monitor the status of the SSU processome (see below). Our proteomic characterization of preribosomal particles depleted of Utp14 revealed a specific loss 
A
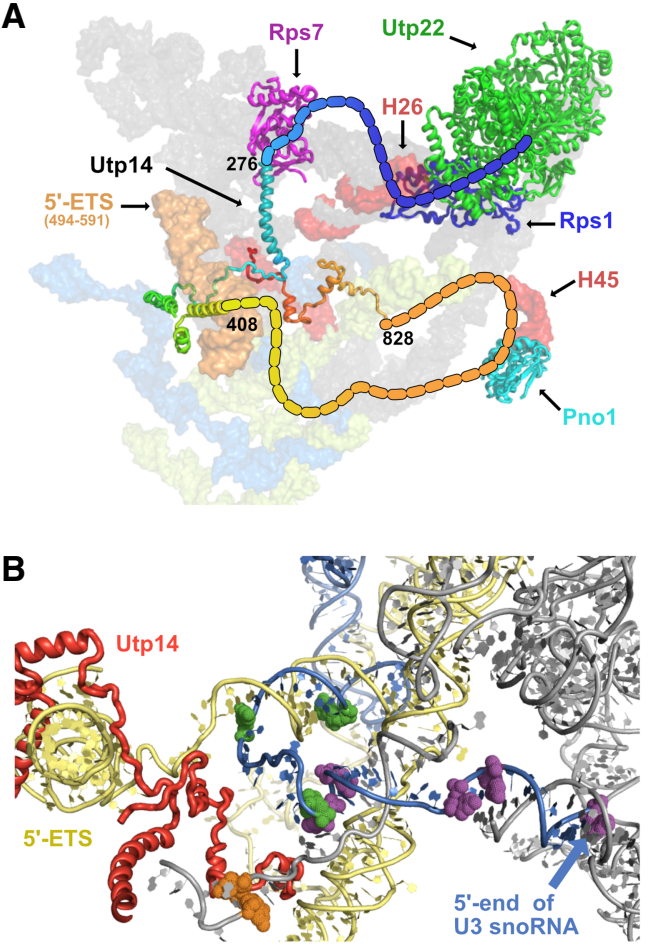

C

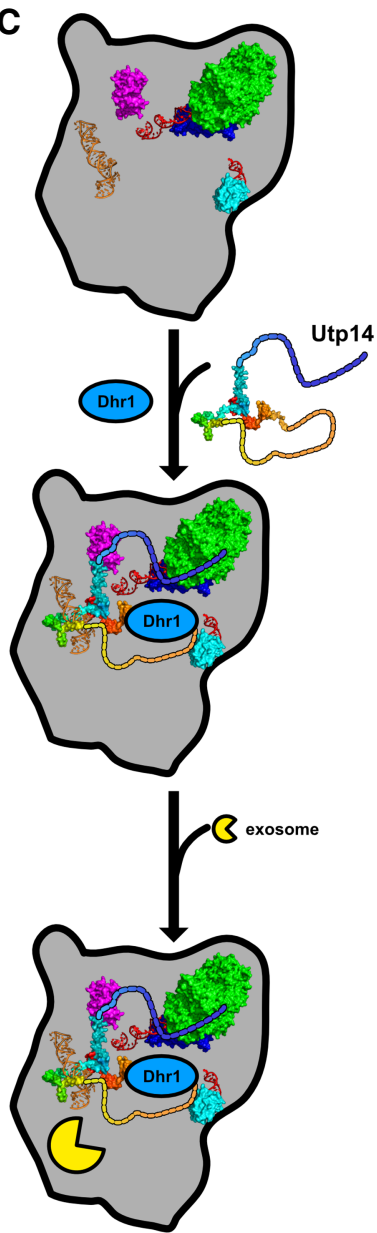

FIGURE 7. Model for Utp14 interaction with the SSU processome. (A) A composite of Utp14 (rainbow; from PDB 5WLC) fitted into an SSU processome structure (PDB 5WYJ) is shown. Beaded lines represent portions of Utp14 not resolved in current structures. Black numbers indicate the residues of Utp14 where the strands of resolved residues end. Rps7 (magenta), Rps22 (orange), Utp22 (green), Rps1 (blue), and Pno1 (cyan) are shown as cartoon representation. Binding site of Utp14 in $18 \mathrm{~S}$ binding sites (red) and in 5'-ETS sites (orange), other regions of $18 \mathrm{~S}$ rRNA (gray), 5-ETS (yellow), and U3 (light blue) are also shown as surface representation. (B) A cartoon representation of the SSU processome (PDB 5WLC) is shown of the U3-rRNA duplexes previously suggested to be the substrate of Dhrl. U3 is shown in blue cartoon with mutations that suppress cold sensitive dhrl (purple) and Dhr1-U3 crosslinks (green) in spheres (Sardana et al. 2015) and rRNA is shown in gray cartoon. Utp14 (red) is shown wrapping around a region of the $5^{\prime}$-ETS (yellow) in close proximity of $\mathrm{U} 3$ and the $\mathrm{A}_{1}$ site (orange spheres). (C) A model for the stepwise entry of Utp14, Dhr1, and exosome into the SSU processome in which the assembly of Utp14 promotes the recruitment of the exosome. Relevant factors and rRNA elements are shown and colored the same as in $A$.

of the exosome, responsible for the exonucleolytic degradation of the $5^{\prime}$-ETS. These results could suggest an unanticipated role for Utp14 in the recruitment of this complex.

\section{Does Utp14 communicate between the $3^{\prime}$ - and $5^{\prime}$-ends of $18 \mathrm{~S}$ rRNA?}

Our protein-RNA crosslinking analysis identified a major binding site for Utp14 across helix 45/D-site of pre-rRNA, the cleavage site that generates the mature $3^{\prime}$-end of $18 \mathrm{~S}$.

We also identified Utp14 binding sites within the $5^{\prime}$-ETS and across the $A_{1}$ site, which generates the mature $5^{\prime}$-end of $18 \mathrm{~S}$ (Fig. 1C,D). To complement our UV crosslinking approach, which did not allow us to determine the domains of Utp14 that were responsible for these RNA interactions, we used yeast-two hybrid analysis to identify interactions between domains of Utp14 and proteins that bound in the vicinity of the two most prominent RNA binding sites, thereby approximating the domains of Utp14 responsible for the major RNA interactions at helix 26 and helix 45/D-site. In addition, several $a$-helices of Utp14 were assigned in recent cryo-EM structures of the SSU processome (Barandun et al. 2017; Cheng et al. 2017), corroborating the interactions of Utp14 that we identified with the $5^{\prime}$-ETS and $A_{1}$ site (Fig. 7B) and identifying the residues of Utp14 that are likely involved in these interactions. Our ability to map Utp14 interactions with helix 26 and helix 45 of the SSU processome suggests that the interactions we characterized and the $5^{\prime}$ $\mathrm{ETS} / \mathrm{A}_{1}$ site interactions are predominantly in the context of the intact SSU processome. In Figure 7A, a C-terminal region of Utp14, between aa 707 and 813 , interacts with the helix 45 and Pnol whereas the $A_{1}$ site and $5^{\prime}$-ETS is recognized by a complex interaction of the extreme $\mathrm{C}$ terminus of Utp14 and overlapping helices from a more central region of Utp14 that wrap around the 5 -ETS. Connecting these two regions is a long unresolved loop that contains the Dhr1 binding site, from aa 565-813. Thus, Utp14 is uniquely positioned to connect the $5^{\prime}$ - and $3^{\prime}$-ends of the $18 \mathrm{~S}$ rRNA, tethering Dhr1 via the intervening loop. A tempting model is that Utp14 actively monitors the status of transcription and assembly of the $3^{\prime}$-end of the small subunit RNA, to signal maturation of SSU processome. Because Utp14 is within close proximity to the residues of U3 that have physical or genetic interactions with Dhr1 (Fig. 7B; Sardana et al. 2013), such a model affords a mechanism for how Utp14 could time the activation of the helicase activity of Dhrl to unwind U3. However, both Utp14 and Dhr1 are present in the mature SSU processome, with U3 remaining bound to rRNA, indicating that additional signals are required to trigger Dhrl unwinding. 


\section{What is the relationship between Utp14 and the nuclear RNA exosome?}

Our proteomic analysis of Utp14 mutant particles suggests that Utp14 is needed for the efficient recruitment of the exosome to the SSU processome. This conclusion is based on our observation that the exosome was severely reduced in Utp14depleted and mutant Utp14 particles compared with Utp14 replete or Dhr1-depleted particles. This difference in exosome abundance was despite the overall similarity in protein composition among these particles and suggests that either Utp14 is directly involved in recruiting the exosome or Utp14 is required for structural rearrangements of the SSU processome that promote its recruitment. To address the notion that Utp14 could directly recruit the exosome, we performed $\mathrm{Y} 2 \mathrm{H}$ analysis between Utp14 and the components of the exosome but could not identify a specific interaction (data not shown). Thus, we favor an indirect effect on exosome recruitment as discussed below.

It was previously shown that Utp 18 recruits the exosome to the $5^{\prime}$-ETS through direct interaction between the N-terminal AIM domain of Utp18 and the Arch domain of Mtr4, the RNA helicase for the nuclear exosome (Thoms et al. 2015). Utp18 is a component of the UTP-B sub complex and binds relatively early to the assembling nascent SSU processome, after the $5^{\prime}$-ETS has been transcribed (ChakerMargot et al. 2015; Zhang et al. 2016), but it is expected that the exosome is not recruited until the SSU processome is fully assembled. To rationalize Utp18 recruitment significantly preceding exosome recruitment, it was proposed that accessibility of the AIM domain to Mtr4 is regulated during assembly of the SSU processome (Thoms et al. 2015). Thus, it is possible that the recruitment of Utp14 regulates accessibility of the AIM domain of Utp18. Limited regions of both Utp14 and Utp18 in the SSU processome have been resolved, revealing that the $\mathrm{C}$ terminus of Utp14 is $\sim 25 \AA$ from the $\mathrm{N}$ terminus of Utp18 (Barandun et al. 2017). However, there has been no reported interaction between Utp14 and
Utp18 in two large-scale Y2H screens (Baßler et al. 2016; Vincent et al. 2018) suggesting that these two proteins may not directly interact. In the SSU processome structures, residues near the $\mathrm{N}$ terminus and the very $\mathrm{C}$ terminus of Utp14 interact with each other near the $A_{1}$ site, and near the expected position of the $A_{0}$ site and approaching Utp18. We note that levels of the exosome were strongly reduced from particles lacking Utp14 in its entirety or lacking either terminus. We suggest that the intramolecular interaction of the $\mathrm{N}$ and C-termini of Utp14 is critical for establishing a structure of the SSU processome that allows the AIM domain of Utp18 to be presented to Mtr4. Such influence on the recruitment of the exosome would be consistent with the idea that Utp14 acts to transmit a signal between the $3^{\prime}$ - and $5^{\prime}$-ends of the SSU processome to recruit the exosome only after the SSU processome has been deemed complete (Fig. 7C).

\section{MATERIALS AND METHODS}

\section{Strains, plasmids, and growth media}

All S. cerevisiae strains and sources are listed in Table 1. AJY4051 was generated by genomic integration of the HIS6-tobacco etch virus (TEV)-protein A (HTP) tag (Granneman et al. 2009) into BY4741. AJY4257 and AJY4258 were generated by genomic integration of ENP1-TAP::HIS3MX6 amplified from AJY2665 into AJY3243 and AJY3711, respectively. All yeast were cultured at $30^{\circ} \mathrm{C}$ in either YPD (2\% peptone, $1 \%$ yeast extract, $2 \%$ dextrose), YPgal ( $2 \%$ peptone, $1 \%$ yeast extract, $1 \%$ galactose), or synthetic dropout (SD) medium containing $2 \%$ dextrose unless otherwise noted. All plasmids used in this study are listed in Table 2.

\section{Yeast two-hybrid (Y2H) analysis}

GAL4 activation domain (AD)-containing vectors were transformed into PJ69-4a, and GAL4 DNA binding domain (BD)-containing vectors were transformed into PJ69-4alpha. Cells harboring these vectors were mated on YPD plates and then replica plated onto SD medium lacking leucine and tryptophan (SD Leu ${ }^{-} \mathrm{Trp}^{-}$

TABLE 1. Strains used in this study

\begin{tabular}{|c|c|c|}
\hline Strain & Genotype & Source \\
\hline AJY2665 & 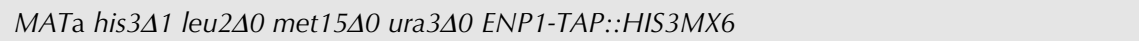 & (Ghaemmaghami et al. 2003) \\
\hline AJY3243 & 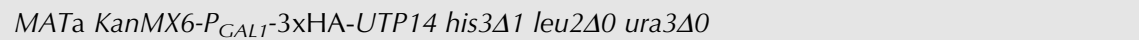 & (Zhu et al. 2016) \\
\hline AJY3711 & 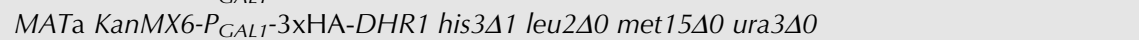 & (Sardana et al. 2015) \\
\hline AJY4051 & $\begin{array}{l}\text { MATa his } 3 \Delta 1 \text { leu } 2 \Delta 0 \text { met } 15 \Delta 0 \\
\text { UTP14-HTP::URA3 }\end{array}$ & This study \\
\hline AJY4257 & 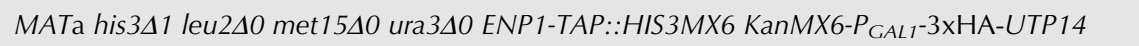 & This study \\
\hline AJY4258 & 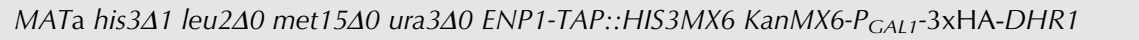 & This study \\
\hline BY4741 & 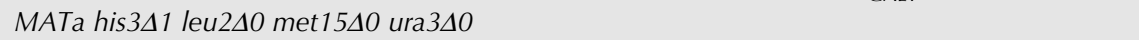 & Open Biosystems \\
\hline PJ69-4a & $\begin{array}{l}\text { MATa trp1-901 leu2-3,112 ura3-52 his3-200 gal4A gal804 LYS2::GAL1-HIS3 GAL2-ADE2 } \\
\text { met2::GAL7-lacZ }\end{array}$ & (James et al. 1996) \\
\hline $\begin{array}{l}\text { PJ69- } \\
\text { 4alpha }\end{array}$ & $\begin{array}{l}\text { MATalpha trp1-901 leu2-3,112 ura3-52 his3-200 gal44 gal804 LYS2::GAL1-HIS3 GAL2-ADE2 } \\
\text { met2::GAL7-lacZ }\end{array}$ & (James et al. 1996) \\
\hline YS360 & 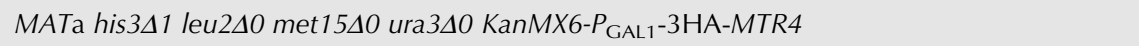 & E Petfalski (unpubl.) \\
\hline
\end{tabular}


TABLE 2. Plasmids used in this study

\begin{tabular}{|c|c|c|}
\hline Plasmid & Description & Source \\
\hline рАCT2 & GAL4AD-HA LEU2 $2 \mu$ & Clontech \\
\hline pAJ2321 & GAL4AD-HA-UTP14 LEU2 $2 \mu$ & (Zhu et al. 2016) \\
\hline pAJ2324 & GAL4BD-c-myc-UTP14 TRP1 $2 \mu$ & This study \\
\hline pAJ2334 & GAL4AD-HA-utp $14_{1-706}$ LEU2 $2 \mu$ & (Zhu et al. 2016) \\
\hline pAJ2335 & GAL4AD-HA-utp 14 $707-899$ LEU2 $2 \mu$ & (Zhu et al. 2016) \\
\hline pAJ2341 & GAL4AD-HA-utp $14_{1-813}$ LEU2 $2 \mu$ & (Zhu et al. 2016) \\
\hline $\mathrm{pAJ} 2342$ & GAL4AD-HA-utp $14_{1-654}$ LEU2 $2 \mu$ & (Zhu et al. 2016) \\
\hline pAJ2343 & GAL4AD-HA-utp $14_{1-564}$ LEU2 $2 \mu$ & (Zhu et al. 2016) \\
\hline pAJ2344 & GAL4AD-HA-utp $14_{1-265}$ LEU2 $2 \mu$ & (Zhu et al. 2016) \\
\hline pAJ2345 & GAL4AD-HA-utp $14_{266-899}$ LEU2 $2 \mu$ & (Zhu et al. 2016) \\
\hline pAJ2346 & GAL4AD-HA-utp 14 ${ }_{565-899}$ LEU2 $2 \mu$ & (Zhu et al. 2016) \\
\hline pAJ2347 & GAL4AD-HA-utp 14 $655-899$ LEU2 $2 \mu$ & (Zhu et al. 2016) \\
\hline pAJ3351 & UTP14-TEV-13myc LEU2 CEN ARS & This study \\
\hline pAJ3422 & utp $14_{1-706}$ URA3 CEN ARS & This study \\
\hline pAJ3426 & utp 14 266-899 URA3 CEN ARS & This study \\
\hline pAJ3624 & GAL4AD-HA-RPS1A LEU2 $2 \mu$ & This study \\
\hline pAJ3625 & GAL4BD-c-myc-utp $14_{1-706}$ TRP1 $2 \mu$ & This study \\
\hline pAJ3626 & GAL4BD-c-myc-utp $14_{1-813} T R P 12 \mu$ & This study \\
\hline pAJ3627 & GAL4BD-c-myc-utp $14_{1-654}$ TRP1 $2 \mu$ & This study \\
\hline pAJ3628 & GAL4BD-c-myc-utp $14_{1-564} T R P 12 \mu$ & This study \\
\hline pAJ3629 & GAL4BD-c-myc-utp $14_{1-265}$ TRP1 $2 \mu$ & This study \\
\hline pAJ3832 & GAL4BD-c-myc-utp $14_{266-899}$ TRP1 $2 \mu$ & This study \\
\hline pAJ3833 & GAL4BD-c-myc-utp 14 $565-899$ TRP1 $2 \mu$ & This study \\
\hline pAJ3834 & GAL4BD-c-myc-utp $14_{655-899}$ TRP1 $2 \mu$ & This study \\
\hline pAJ3835 & GAL4BD-c-myc-utp $1_{707-899}$ TRP1 $2 \mu$ & This study \\
\hline pAJ3846 & GAL4AD-HA-UTP22 LEU2 $2 \mu$ & This study \\
\hline pAJ4043 & utp 14 266-899-TEV-13myc LEU2 CEN ARS & This study \\
\hline pAJ4046 & utp $14_{1-706}$-TEV-13myc LEU2 CEN ARS & This study \\
\hline pAJ4068 & GAL4BD-c-myc-PNO1 TRP1 $2 \mu$ & This study \\
\hline pAJ4176 & UTP14-TAP LEU2 CEN ARS & This study \\
\hline pAJ4177 & utp $14_{1-706}$-TAP LEU2 CEN ARS & This study \\
\hline pAJ4178 & utp14 266-899-TAP LEU2 CEN ARS & This study \\
\hline pAJ4179 & GAL4AD-HA-RPS7A LEU2 $2 \mu$ & This study \\
\hline pAJ4182 & GAL4BD-c-myc-RPS22A TRP1 $2 \mu$ & This study \\
\hline pGADT7 & GAL4AD-HA LEU2 $2 \mu$ & (Patel et al. 2007) \\
\hline pGBKT7 & GAL4BD-c-myc TRP1 $2 \mu$ & (Patel et al. 2007) \\
\hline pRS415 & LEU2 CEN ARS & (Sikorski and Hieter 1989) \\
\hline pRS416 & URA3 CEN ARS & (Sikorski and Hieter 1989) \\
\hline
\end{tabular}

medium) to select for diploid cells harboring both plasmids. The diploid strains were patched on SD $\mathrm{Leu}^{-} \mathrm{Trp}^{-}$and SD $\mathrm{Leu}^{-} \mathrm{Trp}^{-}$ His $^{-}$with or without 3-amino-1,2,4-triazole (3AT) to test for activation of the $U A S_{G A L}-H I S 3$ reporter gene.

\section{UV-crosslinking and analysis of cDNA (CRAC)}

A modified version of the CRAC protocol (Granneman et al. 2009) was performed. Cells from exponential phase cultures AJY4051 and BY4741 were collected, resuspended in PBS on ice and irradiated at $254 \mathrm{~nm}$ using a Stratalinker UV Crosslinker 1800 with 800-1600 mJ/ $\mathrm{cm}^{2}$ and stored at $-80^{\circ} \mathrm{C}$. Cells were resuspended in ice-cold TN150 buffer (50 mM Tris- $\mathrm{HCl} \mathrm{pH}$ 7.8, $150 \mathrm{mM} \mathrm{NaCl}, 0.1 \%$ NP-40, 10 $\mathrm{mM} \beta$-mercaptoethanol [BME], $2 \mathrm{mM} \mathrm{MgCl}_{2}, 1 \mathrm{mM}$ PMSF, and $1 \mu \mathrm{M}$ leupeptin and pepstatin) and extracts were prepared by vortexing with glass beads, and clarified by centrifugation. Extract was incubated with IgG-Sepharose beads (GE Health Care) for $4 \mathrm{~h}$ at $4^{\circ} \mathrm{C}$. The beads were washed with ice-cold TN1000 buffer (TN150, except
$1 \mathrm{M} \mathrm{NaCl}$ ) then with ice-cold TN150 buffer lacking protease inhibitors. Protein was released from the resin using GST-TEV for $4 \mathrm{~h}$ at $16^{\circ} \mathrm{C}$ with rotation. RNAs were digested with RNace-IT Ribonuclease Cocktail (Agilent Technologies) at $37^{\circ} \mathrm{C}$. This mixture was then supplemented to final concentrations of $6 \mathrm{M}$ guanidinium chloride, $10 \mathrm{mM}$ imidazole, and $200 \mathrm{mM} \mathrm{NaCl}$ and bound to Ni-NTA resin (Invitrogen) overnight at $4^{\circ} \mathrm{C}$.

The resin was washed with Buffer I ( 50 mM Tris- $\mathrm{HCl}$ pH 7.8, 300 $\mathrm{mM} \mathrm{NaCl}, 10 \mathrm{mM}$ imidazole, $6 \mathrm{M}$ guanidinium chloride, $0.1 \% \mathrm{NP}$ 40, and $10 \mathrm{mM} \mathrm{BME)}$ and with T4 Polynucleotide kinase (PNK) buffer (70 mM Tris- $\mathrm{HCl} \mathrm{pH} \mathrm{7.6,} 10 \mathrm{mM} \mathrm{MgCl}_{2}$, and $10 \mathrm{mM}$ $\mathrm{BME})$. RNA retained on beads was labeled using T4 PNK and ${ }^{32} \mathrm{P}-\gamma$-ATP (PerkinElmer). T4 PNK also removes the 3 -phosphate remaining from RNase treatment. After labeling, the resin was washed with T4 PNK buffer, and AIR Adenylated Linker A (Bioo Scientific; 5'-rAppCTGTAGGCACCATCAAT/3ddC/-3') was ligated at room temperature for 4-6 h using T4 RNA Ligase 2 (truncated) (New England Biolabs). The protein-RNA complex was eluted from the resin using T4 PNK buffer containing $200 \mathrm{mM}$ imidazole, 
precipitated with $15 \%$ Trichloroacetic acid (TCA) and $2 \mu \mathrm{g}$ bovine serum albumin (BSA), washed with ice cold acetone, air-dried and resuspended in NuPAGE LDS sample buffer. The sample was heated at $70^{\circ} \mathrm{C}$ for $10 \mathrm{~min}$, electrophoresed on a NuPAGE Novex $4 \%-12 \%$ Bis-Tris gel, transferred to nitrocellulose and autoradiographed. A band corresponding approximately to the molecular weight of Utp14 was excised, treated with Protease $\mathrm{K}$ (New England Biolabs) for $2 \mathrm{~h}$ at $55^{\circ} \mathrm{C}$ and the freed RNA was extracted with phenol: chloroform and ethanol precipitated.

Library preparation followed an established protocol for ribosome foot printing (Ingolia et al. 2012). cDNA synthesis was done with the primer ( $5^{\prime}$-(Phos)-AGATCGGAAGAGCGTCGTGTAGGGAAAGA GTGTAGATCTCGGTGGTCGC-(SpC18)-CACTCA-(SpC18)-TTC AGACGTGTGCTCTTCCGATCTATTGATGGTGCCTACAG-3') and either EpiScript RT (Epicentre) or SuperScript III (Invitrogen). Reactions were arrested and RNA hydrolyzed by the addition of $\mathrm{NaOH}$ to $100 \mathrm{mM}$ and heating at $98^{\circ} \mathrm{C}$ for $20 \mathrm{~min}$. cDNA was precipitated with ethanol and resuspended in water. Urea loading buffer (Novex) was added to $1 \times$ and the sample was denatured at $80^{\circ} \mathrm{C}$ for $10 \mathrm{~min}$. The cDNA product was electrophoresed on a $10 \%$ Novex TBE-Urea gel and extracted in TE, followed by precipitation with isopropanol. The purified cDNA product was circularized using CircLigase (Epicentre) incubated at $60^{\circ} \mathrm{C}$ for $2 \mathrm{~h}$, then heat-inactivated at $80^{\circ} \mathrm{C}$ for $10 \mathrm{~min}$. To add adaptors for the first data set, the circularized product was amplified using Phusion DNA polymerase and oligonucleotides AJO 1986 (5'-AATGATACGGCGACCACCGAGA TCTACAC- $3^{\prime}$ ) and ScripMiner Index Primer (\#11 for mock and \#12 for Utp14-HTP). For the second data set, the circularized product was initially amplified using Phusion DNA polymerase and flanking oligonucleotides AJO 2299 (5'-TACACGACGCTCTTC CGATC-3') and AJO 2301 (5'-CAGACGTGTGCTCTTCCGAT C- $\left.3^{\prime}\right)$. The samples were gel purified as described above, resuspended in water and a subsequent PCR was done to add adaptor sequences using Phusion DNA polymerase and the oligonucleotides AJO 2352 (5'-AATGATACGGCGACCACCGAGATCTACACTCTTTC CCTACACGACGCTCTTCCGATCT- $3^{\prime}$ ) and a ScriptMiner Index Primer (\#2 for mock and \#4 for Utp14-HTP). The samples were electrophoresed and purified from the gel as described above and resuspended in water.

The resultant cDNA libraries were sequenced on an Illumina MiSeq platform. The single-end reads were processed using fastx_ trimmer and fastx_clipper (http://hannonlab.cshl.edu/fastx_toolkit/) (v0.0.14) to discard low-quality reads and adapter sequences, respectively. The processed reads were aligned to the yeast genome (Ensembl, version R64-1-1) using Bowtie2 (v2.2.6) (Langmead and Salzberg 2012). The resultant files were analyzed using pyRead Counters.py (v0.5.3) and pyPileup (v0.1.2) (Webb et al. 2014).

\section{Affinity-purification}

Cell growth for affinity-purification is described in the sections below. All steps were carried out at $4^{\circ} \mathrm{C}$ unless otherwise noted. For mass spectrometry, cells were thawed, washed, and resuspended in one volume of Lysis Buffer (20 mM HEPES-KOH pH 8.0, $110 \mathrm{mM}$ KOAc, $40 \mathrm{mM} \mathrm{NaCl}, 1 \mathrm{mM}$ PMSF and benzamidine, and $1 \mu \mathrm{M}$ leupeptin and pepstatin). For northern blot analysis, DEPCtreated and nitrocellulose-filtered reagents were used, and cells were resuspended in 1.5 volume of Lysis Buffer. Extracts were prepared using glass beads and clarified by centrifugation at $18,000 \mathrm{~g}$ for $15 \mathrm{~min}$. Clarified extracts were normalized according to $\mathrm{A}_{260}$, and TritonX-100 was added to a final concentration of $0.1 \%$ $(\mathrm{v} / \mathrm{v})$. Normalized extract was incubated for $90 \mathrm{~min}$ with rabbit IgG (Sigma) coupled to Dynabeads (Invitrogen). The beads were prepared as previously described (Oeffinger et al. 2007). Following binding, the beads were washed twice in Wash Buffer (Lysis Buffer supplemented with $0.1 \%$ TritonX-100) and once with in the Wash Buffer containing $5 \mathrm{mM} \beta \mathrm{ME}$ at $16^{\circ} \mathrm{C}$ prior to resuspension in Elution Buffer (Lysis Buffer supplemented with $5 \mathrm{mM} \beta \mathrm{ME}$ ). For RNA purification, the Elution Buffer was supplemented with $1 \mathrm{U} / \mu \mathrm{L}$ Murine RNase Inhibitor (New England Biolabs). The bound bait-TAP containing complexes were eluted by addition of homemade TEV protease and incubated for $90 \mathrm{~min}$ at $16^{\circ} \mathrm{C}$. The resultant eluates were handled as described in the sections below.

\section{Northern blot analysis}

For Utp14-TAP affinity-purifications, AJY3243 was transformed with the plasmids pAJ4176, pAJ4177, pAJ4178, or pRS415, and YS360 was transformed with pAJ4176. For the Enp1-TAP affinitypurifications, AJY2665, AJY4258, and BY4741 were transformed with pRS416, and AJY4257 was transformed with pRS416, pAJ3422, or pAJ3426. Cell cultures were diluted into in the appropriate SD media containing $2 \%$ glucose at a starting $\mathrm{OD}_{600}$ of 0.1 and cultured for either $7 \mathrm{~h}$ or grown to mid-exponential phase before collection. Cells were stored at $-80^{\circ} \mathrm{C}$ prior to lysis. Affinity-purifications were performed as described above. Affinity-purified and whole cell extract (WCE) RNAs were isolated using the acid-phenol-chloroform method as previously described (Zhu et al. 2016). RNAs were separated by electrophoresis through 1.2\%-agarose MOPS $6 \%$ formaldehyde gel for $4 \mathrm{~h}$ at 50 volts. Northern blotting was performed as previously described ( $\mathrm{Li}$ et al. 2009) using the oligo probes listed in Figure 6 legend, and signal was detected by phosphoimaging on a GE Typhoon FLA9500.

\section{Mass spectrometry and analysis}

For Utp14-TAP affinity-purifications, AJY3243 was transformed with the plasmids pAJ4176, pAJ4177, pAJ4178, or pRS415. Cell cultures were diluted into the appropriate SD media containing $2 \%$ glucose at a starting $\mathrm{OD}_{600}$ of 0.1 and cultured for either $7 \mathrm{~h}$ or to midexponential phase before collection. For the Enp1-TAP affinity-purifications, AJY2665, AJY4257, and AJY4258 cultures were diluted into YPD at a starting $\mathrm{OD}_{600}$ of 0.1 and cultured for either $14 \mathrm{~h}$ or to midexponential phase before collection. Cells were stored at $-80^{\circ} \mathrm{C}$ prior to lysis. Affinity-purifications were done as described above. To isolate factors associated with only preribosomal particles for mass spectrometry, the eluate was overlaid onto a sucrose cushion (15\% D-sucrose, $20 \mathrm{mM}$ HEPES-KOH pH 8.0, $110 \mathrm{mM} \mathrm{KOAc,}$ $40 \mathrm{mM} \mathrm{NaCl}$ ) then centrifuged at 70,000 rpm for $15 \mathrm{~min}$ on a Beckman Coulter TLA100 rotor.

To perform peptide identification by mass spectrometry, we loaded approximately equal amounts of protein from the pellet fraction onto a NuPAGE Novex 4\%-12\% Bis-Tris gel. Proteins were electrophoresed slightly into the gel then stained with Coomassie. A small gel slice containing the proteins was excised and dehydrated with acetonitrile, reduced with $10 \mathrm{mM}$ DTT, then alkylated with 50 $\mathrm{mM}$ iodoacetamide. The gel slice was washed with $100 \mathrm{mM}$ ammonium bicarbonate then dehydrated with acetonitrile. In-gel 
digestion was performed using trypsin (Peirce) in $50 \mathrm{mM}$ ammonium bicarbonate overnight at $37^{\circ} \mathrm{C}$. Peptides were extracted with $5 \%$ $(\mathrm{w} / \mathrm{v})$ formic acid treatment, then with 1:2(v/v) 5\% formic acid: $100 \%$ acetonitrile treatment. These solutions were combined with the trypsin digest solution and desalted. The resultant peptides were run for $1 \mathrm{~h}$ on a Dionex LC and Orbitrap Fusion 1 for LC-MS/MS.

Mass spectrometry data were processed in Scaffold v4.8.3 (Proteome Software, Inc.), and a protein threshold of 99\% minimum and two peptides minimum, and peptide threshold of $0.1 \%$ FDR was applied. The data were exported to Microsoft Excel, then custom Python 2.7 scripts were used to calculate the relative spectral abundance factor (RSAF) for each protein by dividing the total number of spectral counts by the molecular weight. For each sample, the RSAF value of each protein was normalized to the mean RSAF value of the UTP-B subcomplex in Microsoft Excel to reflect relative stoichiometry as done previously (Zhang et al. 2016). Supplemental File 2 contains relevant spectral counts and processed data from the mass spectrometry experiments.

\section{Sucrose density gradient fractionation and western blot analysis}

BY4741 was transformed with pAJ3351, pAJ4043, or pAJ4046. Cells were diluted to $\mathrm{OD}_{600}$ of 0.1 in of $\mathrm{SD} \mathrm{Leu}{ }^{-}$media and grown to midexponential phase. Cycloheximide (CHX) was added to a concentration of $50 \mu \mathrm{g} / \mathrm{mL}$, and the cultures were shaken for $10 \mathrm{~min}$ at $30^{\circ} \mathrm{C}$. The cells were poured over ice, collected by centrifugation and stored at $-80^{\circ} \mathrm{C}$. Sucrose density gradients and fractionation were performed as described previously (Sardana et al. 2014), except the buffer consisted of $50 \mathrm{mM}$ Tris- $\mathrm{HCl} \mathrm{pH} \mathrm{7.5,} 100 \mathrm{mM} \mathrm{KCl}, 5 \mathrm{mM}$ $\mathrm{MgCl}_{2}, 50 \mu \mathrm{g} / \mathrm{mL} \mathrm{CHX}, 1 \mathrm{mM}$ PMSF and benzamidine, and $1 \mu \mathrm{M}$ leupeptin and pepstatin. Proteins were precipitated with $25 \%$ (v/v) trichloroacetic acid followed by centrifugation, washed with $100 \%$ acetone, then resuspended in Laemmli buffer and heated at $99^{\circ} \mathrm{C}$ for 3 min prior to separation on $4 \%-15 \%$ SDS-PAGE gels. For the western blot analysis, antibodies were anti-c-myc monoclonal 9e10 antibody (Biolgend), and goat anti-mouse IRDye $800 \mathrm{CW}$ (Li-Cor). Blots were imaged with an Odyssey CLx Infrared Imaging System (Li-Cor).

\section{DATA DEPOSITION}

All relevant sequencing data have been deposited in the Gene Expression Omnibus (GEO) database (http://www.ncbi.nlm.nih. gov/geo/) with the accession number GSE115748. Python scripts are available upon request.

\section{SUPPLEMENTAL MATERIAL}

Supplemental material is available for this article.

\section{ACKNOWLEDGMENTS}

We wish to thank J. Recchia-Rife for his assistance with cloning and J.A. Hussmann for his initial assistance with the CRAC data analysis. We thank Dr. E. Petfalski for strain YS360. This work was supported by National Institutes of Health grant NIH GM108823 to A.W.J.
The Proteomics Facility in the Center for Biomedical Research Support at the University of Texas at Austin is supported in part by Cancer Prevention and Research Institute of Texas grant RP110782.

Received March 12, 2018; accepted June 17, 2018.

\section{REFERENCES}

Baßler J, Ahmed YL, Kallas M, Kornprobst M, Calviño FR, Gnädig M, Thoms M, Stier G, Ismail S, Kharde S, et al. 2016. Interaction network of the ribosome assembly machinery from a eukaryotic thermophile. Protein Sci 26: 327-342.

Barandun J, Chaker-Margot M, Hunziker M, Molloy KR, Chait BT, Klinge S. 2017. The complete structure of the small-subunit processome. Nat Struct Mol Biol 24: 944-953.

Barandun J, Hunziker M, Klinge S. 2018. Assembly and structure of the SSU processome- a nucleolar precursor of the small ribosomal subunit. Curr Opin Struct Biol 49: 85-93.

Ben-Shem A, Garreau de Loubresse N, Melnikov S, Jenner L, Yusupova G, Yusupov M. 2011. The structure of the eukaryotic ribosome at $3.0 \AA$ resolution. Science 334: 1524-1529.

Chaker-Margot M, Hunziker M, Barandun J, Dill BD, Klinge S. 2015. Stage-specific assembly events of the 6-MDa small-subunit processome initiate eukaryotic ribosome biogenesis. Nat Struct Mol Biol 22: 920-923.

Chaker-Margot M, Barandun J, Hunziker M, Klinge S. 2017. Architecture of the yeast small subunit processome. Science 355: eaal1880.

Cheng J, Kellner N, Berninghausen O, Hurt E, Beckmann R. 2017. 3.2$\AA$-resolution structure of the $90 \mathrm{~S}$ preribosome before A1 pre-rRNA cleavage. Nat Struct Mol Biol 24: 954-964.

Choque E, Schneider C, Gadal O, Dez C. 2018. Turnover of aberrant pre-40S pre-ribosomal particles is initiated by a novel endonucleolytic decay pathway. Nucleic Acids Res 46: 4699-4714.

Dragon F, Gallagher JEG, Compagnone-Post PA, Mitchell BM, Porwancher KA, Wehner KA, Wormsley S, Settlage RE, Shabanowitz J, Osheim Y, et al. 2002. A large nucleolar U3 ribonucleoprotein required for 18S ribosomal RNA biogenesis. Nature 417: 967-970.

Dutca LM, Gallagher JEG, Baserga SJ. 2011. The initial U3 snoRNA:prerRNA base pairing interaction required for pre- $18 \mathrm{~S}$ rRNA folding revealed by in vivo chemical probing. Nucleic Acids Res 39: 5164-5180.

Ferreira-Cerca S, Pöll G, Gleizes P-E, Tschochner H, Milkereit P. 2005. Roles of eukaryotic ribosomal proteins in maturation and transport of pre-18S rRNA and ribosome function. Mol Cell 20: 263-275.

Ghaemmaghami S, Huh W-K, Bower K, Howson RW, Belle A, Dephoure N, O'Shea EK, Weissman JS. 2003. Global analysis of protein expression in yeast. Nature 425: 737-741.

Granneman S, Kudla G, Petfalski E, Tollervey D. 2009. Identification of protein binding sites on U3 snoRNA and pre-rRNA by UV crosslinking and high-throughput analysis of cDNAs. Proc Natl Acad Sci 106: 9613-9618.

Heuer A, Thomson E, Schmidt C, Berninghausen O, Becker T, Hurt E, Beckmann R. 2017. Cryo-EM structure of a late pre-40S ribosomal subunit from Saccharomyces cerevisiae. Elife 6: e30189.

Ingolia NT, Brar GA, Rouskin S, McGeachy AM, Weissman JS. 2012. The ribosome profiling strategy for monitoring translation in vivo by deep sequencing of ribosome-protected mRNA fragments. Nat Protoc 7: 1534-1550.

James P, Halladay J, Craig EA. 1996. Genomic libraries and a host strain designed for highly efficient two-hybrid selection in yeast. Genetics 144: 1425-1436.

Johnson MC, Ghalei H, Doxtader KA, Karbstein K, Stroupe ME. 2017. Structural heterogeneity in pre-40S ribosomes. Structure 25: 329-340.

Kornprobst M, Turk M, Kellner N, Cheng J, Flemming D, Koš-Braun I, Koš M, Thoms M, Berninghausen O, Beckmann R, et al. 2016. 


\section{Black et al.}

Architecture of the $90 \mathrm{~S}$ pre-ribosome: a structural view on the birth of the eukaryotic ribosome. Cell 166: 380-393.

Kressler D, Hurt E, Baßler J. 2017. A puzzle of life: crafting ribosomal subunits. Trends Biochem Sci 42: 640-654.

Langmead B, Salzberg SL. 2012. Fast gapped-read alignment with Bowtie 2. Nat Methods 9: 357-359.

Li Z, Lee I, Moradi E, Hung N-J, Johnson AW, Marcotte EM. 2009. Rational extension of the ribosome biogenesis pathway using network-guided genetics. PLoS Biol 7: e1000213.

Lin J, Lu J, Feng Y, Sun M, Ye K. 2013. An RNA-binding complex involved in ribosome biogenesis contains a protein with homology to tRNA CCA-adding enzyme. PLoS Biol 11: e1001669.

Martin R, Hackert P, Ruprecht M, Simm S, Brüning L, Mirus O, Sloan KE, Kudla G, Schleiff E. 2014. A pre-ribosomal RNA interaction network involving snoRNAs and the pre-ribosomal RNA interaction network involving snoRNAs and the Rok1 helicase. RNA 20: 1173-1182.

Oeffinger M, Wei KE, Rogers R, DeGrasse JA, Chait BT, Aitchison JD, Rout MP. 2007. Comprehensive analysis of diverse ribonucleoprotein complexes. Nat Methods 4: 951-956.

Patel SS, Belmont BJ, Sante JM, Rexach MF. 2007. Natively unfolded nucleoporins gate protein diffusion across the nuclear pore complex. Cell 129: 83-96.

Peña C, Hurt E, Panse VG. 2017. Eukaryotic ribosome assembly, transport and quality control. Nat Struct Mol Biol 24: 689-699.

Sardana R, White JP, Johnson AW. 2013. The rRNA methyltransferase Bud23 shows functional interaction with components of the SSU processome and RNase MRP. RNA 19: 828-840.

Sardana R, Zhu J, Gill M, Johnson AW. 2014. Physical and functional interaction between the methyltransferase Bud23 and the essential DEAH-box RNA helicase Ecm16. Mol Cell Biol 34: 2208-2220.

Sardana R, Liu X, Granneman S, Zhu J, Gill M, Papoulas O, Marcotte EM, Tollervey D, Correll CC, Johnson AW. 2015. The DEAH-box helicase Dhr1 dissociates U3 from the pre-rRNA to promote formation of the central pseudoknot. PLoS Biol 13: e1002083.
Sikorski RS, Hieter P. 1989. A system of shuttle vectors and yeast host strains designed for efficient manipulation of DNA in Saccharomyces cerevisiae. Genetics 122: 19-27.

Sloan KE, Warda AS, Sharma S, Entian K-D, Lafontaine DLJ, Bohnsack MT. 2016. Tuning the ribosome: the influence of rRNA modification on eukaryotic ribosome biogenesis and function. RNA Biol 408: 1-16.

Sturm M, Cheng J, Baßler J, Beckmann R, Hurt E. 2017. Interdependent action of KH domain proteins Krr1 and Dim2 drive the 40S platform assembly. Nat Commun 8: 2213.

Sun Q, Zhu X, Qi J, An W, Lan P, Tan D, Chen R, Wang B, Zheng S, Zhang C, et al. 2017. Molecular architecture of the 90 S small subunit pre-ribosome. Elife 6: e22086.

Thoms M, Thomson E, Baßler J, Gnädig M, Griesel S, Hurt E. 2015. The exosome is recruited to RNA substrates through specific adaptor proteins. Cell 162: 1029-1038.

Vanrobays E, Gélugne J-P, Caizergues-Ferrer M, Lafontaine DLJ. 2004. Dim2p, a KH-domain protein required for small ribosomal subunit synthesis. RNA 10: 645-656.

Vincent NG, Charette JM, Baserga SJ. 2018. The SSU processome interactome in Saccharomyces cerevisiae reveals novel protein subcomplexes. RNA 24: 77-89.

Webb S, Hector RD, Kudla G, Granneman S. 2014. PAR-CLIP data indicate that Nrd1-Nab3-dependent transcription termination regulates expression of hundreds of protein coding genes in yeast. Genome Biol 15: R8.

Woolford JL, Baserga SJ. 2013. Ribosome biogenesis in the yeast Saccharomyces cerevisiae. Genetics 195: 643-681.

Zhang L, Wu C, Cai G, Chen S, Ye K. 2016. Stepwise and dynamic assembly of the earliest precursors of small ribosomal subunits in yeast. Genes Dev 30: 718-732.

Zhu J, Liu X, Anjos M, Correll CC, Johnson AW. 2016. Utp14 recruits and activates the RNA helicase Dhr1 to undock U3 snoRNA from the preribosome. Mol Cell Biol 36: 965-978. 

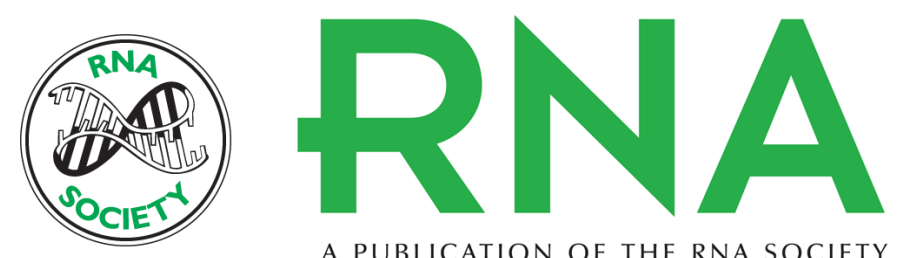

A PUBLICATION OF THE RNA SOCIETY

\section{Utp14 interaction with the small subunit processome}

Joshua J. Black, Zhaohui Wang, Lisa M. Goering, et al.

RNA 2018 24: 1214-1228 originally published online June 20, 2018

Access the most recent version at doi:10.1261/rna.066373.118

Supplemental Material

References

Creative Commons License

Email Alerting Service
http://rnajournal.cshlp.org/content/suppl/2018/06/20/rna.066373.118.DC1

This article cites 40 articles, 13 of which can be accessed free at: http://rnajournal.cshlp.org/content/24/9/1214.full.html\#ref-list-1

This article is distributed exclusively by the RNA Society for the first 12 months after the full-issue publication date (see http://rnajournal.cshlp.org/site/misc/terms.xhtml). After 12 months, it is available under a Creative Commons License (Attribution-NonCommercial 4.0 International), as described at http://creativecommons.org/licenses/by-nc/4.0/.

Receive free email alerts when new articles cite this article - sign up in the box at the top right corner of the article or click here. 